\title{
Dating Business Cycle Turning Points for the French Economy: a MS-DFM approach*
}

\author{
June 9,2015
}

Catherine Doz ${ }^{1}$, Anna Petronevich ${ }^{2}$

\begin{abstract}
The official institutions (NBER, OECD, CEPR and others) provide business cycle chronology with a lag from 3 months up to several years. Markov-Switching Dynamic Factor Model (MS-DFM) allows to produce the turning points more timely. Maximum Likelihood estimation of the model can be run only for a very small set of information. The two-step estimation method can accommodate much bigger information sets. In this paper we apply one-step and two-step approaches to the French data and compare their performance. Both methods give qualitatively similar results and prove to reproduce the OECD business cycle chronology on the 1993-2014 monthly sample well. We find that the two-step method is more precise in determining the beginnings and the ends of recessions. Also, both methods produce extra signals corresponding to downturns which were too short to belong to OECD chronology of recessions.
\end{abstract}

JEL Classification: C32, C34, C55, E32

Keywords: Dynamic factor models, Markov switching models, business cycle turning points

\footnotetext{
*The authors thank the editors and two anonymous referees for useful remarks. All remaining errors are ours. We also acknowledge financial support by the European Commission in the framework of the European Doctorate in Economics - Erasmus Mundus (EDEEM).

${ }^{1}$ Paris School of Economics and Université Paris 1 Panthéon-Sorbonne

${ }^{2}$ Paris School of Economics and Université Paris 1 Panthéon-Sorbonne
} 


\section{Introduction}

The knowledge of the current state of the economic cycle is essential for policymakers. However, it is not easy to determine. The first problem is that a certain time is to pass before the official institutions announce the state of today. NBER and CEPR produce the reference economic cycle dating for the USA and Europe, respectively, on a basis of a consensus of expert opinions with a lag of several months or years. The OECD dating for Europe also appears with a lag of up to 3 months as it is based on the quarterly GDP series. Other institutions, such as ECRI ${ }^{3}$, provide dating with at least one year lag. Besides the timing, the second complicated issue is the identification of the list of series which can serve as indicators of the economic cycle. Finally, it is not obvious which method should be used to determine turning points. Several procedures exist, and the results are likely to differ. In this paper, we attempt to tackle these three problems in case of the French economic cycles on the basis of the Markov Switching Dynamic Factor Model.

The Dynamic Factor Model with Markov Switching (MS-DFM) was first suggested by Diebold and Rudenbusch (1996) ${ }^{4}$. This paper relies on the seminal paper by Hamilton (1989) which applies a univariate Markov-Switching model to business cycle analysis. It was then formalized for the multivariate case by Kim (1994) and by Kim and Yoo (1995) and used afterwards by Chauvet (1998), Kim and Nelson (1998), Kaufmann (1998). The model allows to consider two features of an economic cycle as described by Burns and Mitchell (1946), namely the comovement of individual economic series and the division of an economic cycle into two distinct regimes, recession and expansion. Thus, the common factor of the economic series contains the information on the dynamics of the economic activity, while the two-regime pattern is captured by allowing the parameters of the factor dynamics to follow a Markov-chain process. While the original model assumes switches in mean, other types of non-linearity were proposed by Kholodilin (2002a, 2002b), Dolega (2007), Bessec and Bouabdallah (2007) where the slope of factors or exogenous variables is state dependent; or by Chauvet (1998, 1999), Kholodilin (2002a, 2002b), Kholodilin and Yao (2004), Anas et al., (2007) where the variance of idiosyncratic component is state dependent; and lastly by Chauvet and Potter (1998) and Carvalho and Lopesa (2006) where the authors allow for structural breaks in factor loadings.

The MS-DFM model can be estimated either in one or two steps. The one-step method implies estimation of parameters of the model and factor simultaneously, under specific assumptions on the dynamics of the factor. The two-step method consists of 1) extraction of a composite indicator reflecting the economic activity (the factor); 2) estimation of the parameters of the univariate Markov-Switching model on the factor series. As usual, each method has its advantages and disadvantages. The one-step approach is given more favor in the literature since, within this method, the extracted factor is designed so that it has Markov-switching dynamics. On the other hand, the one-step approach is subject to convergence problems and is more time-consuming, since the number of parameters to estimate is much larger than in the case of two-step procedure and increases with the number of series in the database. Thus, it is necessary to choose a set of variables that would reflect the oscillations of the economic activity correctly. The two-step procedure is much easier to implement, is flexible in model specification and does not put any restrictions on the number of series by default. This is why it has been used in a number of papers, for example by

\footnotetext{
${ }^{3}$ Economic Cycle Research Institute, private organization.

${ }^{4}$ The working paper version appeared in 1994 in NBER Working Papers 4643.
} 
Chauvet and Senyuz (2008), Darné and Ferrara (2011), Bessec and Bouabdallah (2014) and others. However, Camacho et al., (2012) argued that this method may face misspecification issues, as the factor extracted on the first step is not supposed to have a non-linear dynamics. More precisely, the authors argued that, when estimated with a linear DFM, the factor may give too much weight to the past values of underlying series, thus being too slow to reflect the most recent changes. In this paper we analyze and compare the results of these two estimation methods to identify the turning points of the growth rate cycle of the French economy. We estimate the MS-DFM for the period May 1993 - March 2014 via the two-step method on a large database containing 151 series and via the one-step method on 4 series, as suggested by the original paper of Kim and Yoo (1995). We show evidence that, when the factor is estimated by PCA on the first step, and when the number of series is sufficiently large, the two-step estimation method can, in fact, provide satisfactory results.

We determine the key economic indicators that are able to give early and accurate signals on the current state of the growth rate cycle for the one-step method. We then compare the results obtained via the one-step results to the two-step results. This analysis is a contribution to the existing literature on the comparison of the two methods, notably the paper by Camacho et al. (2012), who argued that the one-step method is preferable to the two-step one, although its marginal gains diminish as the quality of the indicators increases and as more indicators are used to identify the non-linear signal. Their result was illustrated on four series of the Stock-Watson coincident index for the US while we perform the comparison on an extensive dataset of 151 French series. Secondly, we decrease the degree of subjectivity regarding the choice of variables for the one-step method by testing all possible combinations of 25 main economic indicators. This is a contribution to existing works on the alternative economic cycle chronologies for France estimated on a small dataset by Kaufmann (2000), Gregoir and Lenglart (2000), Kholodilin (2006), Chen (2007), Chauvet and Yu (2007), Dueker and Sola (2008), Darné and Ferrara (2011). Finally, we conclude that although both methods provide valid results and outperform the reference dating in timing of the announcement of a current state of the business cycle, the two-step method has the advantage to be easy to implement and to detect quickly the temporal deterioration in an economy.

The structure of the paper is as follows: in the second section we describe the baseline Markov Switching Dynamic Factor model and its two estimation methods. In the third section we discuss the dataset and the measures of quality that we use to compare the approaches. The fourth section is devoted to the description of one-step and two-step estimation results and to their comparison. Section 5 concludes.

\section{The model and the estimation methods}

\section{$2.1 \quad$ The model}

The general framework for Markov switching factor models has been first settled by Kim (1994) and was then used by Kim and Yoo (1995) to study the US business cycle. In the present paper, we take the same kind of specification as in Kim and Yoo (1995), and we assume that the growth rate cycle of the economic activity has only two regimes (or states), associated with its low and high levels. The economic activity itself is represented by an unobservable factor, which summarizes the common dynamics of several observable variables. It is assumed that the switch between regimes happens instantaneously, without any transition period (as is considered, for example, by STAR 
family models). This assumption can be motivated by the fact that the transition period before deep crises is normally short enough to be omitted. For example, the growth rate of French GDP fell from $0.5 \%$ in the first quarter of 2008 to $-0.51 \%$ in the second quarter of the same year, and further down to $-1.59 \%$ in the first quarter of $2009^{5}$.

The model is thus decomposed into two equations, the first one defining the factor model, and the second one describing the Markov switching autoregressive model which is assumed for the common factor. More precisely, in the first equation, each series of the information set is decomposed into the sum of a common component (the common factor loads each of the observable series with a specific weight) and an idiosyncratic component:

$$
y_{t}=\gamma f_{t}+z_{t},
$$

where $y_{t}$ is a $N \times 1$ vector of economic indicators, $f_{t}$ is a univariate common factor, $z_{t}$ is a $N \times 1$ vector of idiosyncratic components, which is uncorrelated with $f_{t}$ at all leads and lags, $\gamma$ is a $N \times 1$ vector. In this equation all series are supposed to be stationary, so that some of the components of $y_{t}$ may be the first differences of an initial non stationary economic indicator.

The second equation describes the behavior of the factor $f_{t}$, which is supposed to follow an autoregressive Markov Switching process with constant transition probabilities ${ }^{6}$. We consider, in most of the paper, that the change in regime affects only the level of the constant with the high level corresponding to the expansion state and the low level to the recession state. Following Kim and Yoo (1995), we also suppose that the lag polynomial $\phi(L)$ is of order 2 so that:

$$
f_{t}=\beta_{S_{t}}+\phi_{1} f_{t-1}+\phi_{2} f_{t-2}+\eta_{t},
$$

where $\eta_{t} \sim$ i.i.d. $\mathcal{N}(0,1)$, and $\phi_{1}$ and $\phi_{2}$ are the autoregressive coefficients.

The switching mean is defined as:

$$
\beta_{S_{t}}=\beta_{0}\left(1-S_{t}\right)+\beta_{1} S_{t},
$$

where $S_{t}$ follows an ergodic Markov chain, i.e.

$$
\operatorname{Pr}\left(S_{t}=j \mid S_{t-1}=i, S_{t-2}=k, \ldots\right)=\operatorname{Pr}\left(S_{t}=j \mid S_{t-1}=i\right)=p_{i j} .
$$

As it is assumed that there are two states only, $S_{t}$ switches states according to transition probabilities matrix defined as $\left[\begin{array}{cc}p_{0} & 1-p_{0} \\ 1-p_{1} & p_{1}\end{array}\right]$, where

$$
\operatorname{Pr}\left(S_{t}=0 \mid S_{t-1}=0\right)=p_{0} \text { and } \operatorname{Pr}\left(S_{t}=1 \mid S_{t-1}=1\right)=p_{1} .
$$

There is no restriction on the duration of each state, and the states are defined pointwise, i.e. a recession period may last one month only.

\footnotetext{
${ }^{5}$ INSEE, France, Gross Domestic Product, Total, Contribution to Growth, Calendar Adjusted, Constant Prices, SA, Chained, Change P/P

${ }^{6} \mathrm{Kim}$ and Yoo (1995) showed that although the assumption of the time dependent probabilities improves the quality of the model, the gain in terms of loglikelihood is not very large.
} 
Following Kim and Yoo (1995), we also assume that the idiosyncratic components $z_{i t}$ 's are mutually uncorrelated at all leads and lags, that each of them follows an autoregressive process with a lag polynomial $\psi_{i}(L)$, and that the degree of this polynomial is 2 . Thus:

$$
z_{t}=\psi_{1} z_{t-1}+\psi_{2} z_{t-2}+\varepsilon_{t}
$$

where $\psi_{1}$ and $\psi_{2}$ are diagonal matrices of coefficients, $\varepsilon_{t} \sim \mathcal{N}(0, \Sigma)$, and $\Sigma$ a is diagonal matrix.

The model can be cast into state-space form:

$$
\begin{gathered}
y_{t}=B \alpha_{t}, \\
\alpha_{t}=T \alpha_{t-1}+\mu_{S_{t}}+R w_{t},
\end{gathered}
$$

where $\alpha_{t}$ is the state variable,

$\alpha_{t}=\left(f_{t}, f_{t-1}, z_{t}^{\prime}, z_{t-1}^{\prime}\right)^{\prime}$, with $z_{t}=\left(z_{1 t}, \ldots, z_{N t}\right)^{\prime}$

$w_{t}=\left(\eta_{t}, \varepsilon_{t}^{\prime}\right)^{\prime}$, with $\varepsilon_{t}=\left(\varepsilon_{1 t}, \ldots, \varepsilon_{N t}\right)^{\prime}$

$E\left(w_{t} w_{t}^{\prime}\right)=Q=\operatorname{diag}\left\{1, \sigma_{1}^{2}, \ldots, \sigma_{N}^{2}\right\}$,

$\mu_{s_{t}}=\left(\beta_{s_{t}}, 0_{(2 N+1) \times 1}^{\prime}\right)^{\prime}$

and $B, T$ and $R$ are corresponding coefficient matrices.

More explicitly, the state-space representation takes the form:

$$
\begin{gathered}
y_{t}=\left(\begin{array}{llll}
\gamma & 0 & I_{N} & 0
\end{array}\right)\left(\begin{array}{c}
f_{t} \\
f_{t-1} \\
z_{t} \\
z_{t-1}
\end{array}\right), \\
\left(\begin{array}{c}
f_{t} \\
f_{t-1} \\
z_{t} \\
z_{t-1}
\end{array}\right)=\left(\begin{array}{cccc}
\phi_{1} & \phi_{2} & 0 & 0 \\
1 & 0 & 0 & 0 \\
0 & 0 & \psi_{1} & \psi_{2} \\
0 & 0 & I_{N} & 0
\end{array}\right)\left(\begin{array}{c}
f_{t-1} \\
f_{t-2} \\
z_{t-1} \\
z_{t-2}
\end{array}\right)+\left(\begin{array}{c}
\beta_{s_{t}} \\
0 \\
0 \\
0
\end{array}\right)+\left(\begin{array}{cc}
1 & 0 \\
0 & 0 \\
0 & I_{N} \\
0 & 0
\end{array}\right)\left(\begin{array}{l}
\eta_{1} \\
\varepsilon_{t}
\end{array}\right) .
\end{gathered}
$$

\subsection{One-step estimation method}

In this section, we recall the estimation method which has been introduced by Kim (1994) and Kim and Yoo (1995): it is a one-step method, but it can be employed only for a small set of observable series. Using the state-space representation of the model, which is given by equations (7) and (8), the Kalman filter can be written conditionally to the realizations of the state variable at time $t$ and $t-1$. If $X_{t \mid t-1}^{(j, i)}$ denotes the predicted value of the variable $X_{t}$ conditional on the information available up to $t-1$ and on the realizations $S_{t}=j$ and $S_{t-1}=i$, the Kalman filter formulas are the following:

Prediction step

$$
\alpha_{t \mid t-1}^{(j, i)}=T \alpha_{t-1 \mid t-1}^{(i)}+\mu_{S_{t}}^{(j)}
$$




$$
P_{t \mid t-1}^{(j, i)}=T P_{t-1 \mid t-1}^{(i)} T^{\prime}+R Q R^{\prime}
$$

Error step

$$
\begin{gathered}
v_{t \mid t-1}^{(j, i)}=y_{t}-B \alpha_{t \mid t-1}^{(j, i)}, \\
\operatorname{Var}\left(v_{t \mid t-1}^{(j, i)}\right)=H_{t \mid t-1}^{(j, i)}=B P_{t \mid t-1}^{(j, i)} B^{\prime},
\end{gathered}
$$

Updating step

$$
\begin{gathered}
\alpha_{t \mid t}^{(j, i)}=\alpha_{t \mid t-1}^{(j, i)}+K_{t}^{(j, i)} v_{t \mid t-1}^{(j, i)}, \\
P_{t \mid t}^{(j, i)}=\left(I_{(2 N+2)}-K_{t}^{(j, i)} B\right) P_{t \mid t-1}^{(j, i)} .
\end{gathered}
$$

The Kalman gain $K_{t}^{(j, i)}$ is given by

$$
K_{t}^{(j, i)}=P_{t \mid t-1}^{(j, i)} B^{\prime}\left(H_{t \mid t-1}^{(j, i)}\right)^{-1} .
$$

As mentioned in Kim (1994) or Kim and Yoo (1995), it is possible to introduce some approximations in order to make the Kalman filter implementable in practice. Instead of producing 4 sets of values $\alpha_{t \mid t}^{(j, i)}$ and $P_{t \mid t}^{(j, i)}$ at each step $t$, according to the 4 possible values of $(i, j)$, the idea is to approximate $\alpha_{t \mid t}$ and $P_{t \mid t}$ by taking weighted averages over states at $t-1$, which allows to collapse these 4 sets of values into 2 . Thus, the following approximations are used ${ }^{7}$ :

$$
\begin{gathered}
\alpha_{t \mid t}^{j}=\frac{\sum_{i=0}^{1} \operatorname{Pr}\left(S=i, S_{t}=j \mid I_{t}, \theta\right) \alpha_{t \mid t}^{(j, i)}}{\operatorname{Pr}\left(S_{t}=j \mid I_{t}, \theta\right)}, \\
P_{t \mid t}^{j}=\frac{\sum_{i=0}^{1} \operatorname{Pr}\left(S_{t-1}=i, S_{t}=j \mid I_{t}, \theta\right)\left(P_{t \mid t}^{(j, i)}+\left(\alpha_{t \mid t}^{j}-\alpha_{t \mid t}^{(j, i)}\right)\left(\alpha_{t \mid t}^{j}-\alpha_{t \mid t}^{(j, i)}\right)^{\prime}\right)}{\operatorname{Pr}\left(S=j \mid I_{t}, \theta\right)} .
\end{gathered}
$$

The filtered probability of being in state $j \in\{0 ; 1\}$ in period $t$ conditional on the information available up to $t$ can then be computed using Hamilton's filter (see Hamilton (1989)) and the previous Kalman filter formulas.

More precisely, if $\theta=\left(\phi_{1}, \phi_{2}, \operatorname{diag}\left(\psi_{1}\right), \operatorname{diag}\left(\psi_{2}\right), \gamma, \sigma_{1}^{2}, \ldots, \sigma_{N}^{2}, \beta_{0}, \beta_{1}, p_{0}, p_{1}\right)^{\prime}$ is the vector of unknown parameters, if $f(\cdot)$ is the Gaussian density function, and if $I_{t}$ is the information set available at $t$, it is possible to compute the filtered probability $\operatorname{Pr}\left(S_{t}=j \mid I_{t}, \theta\right)$ through the following equations (based on Bayes' theorem):

$$
\operatorname{Pr}\left(S_{t}=j \mid I_{t}\right)=\sum_{i=0}^{1} \operatorname{Pr}\left(S=j, S_{t-1}=i \mid I_{t}, \theta\right)
$$

where

\footnotetext{
${ }^{7}$ For further details see Kim (1994) and the references therein
} 


$$
\begin{aligned}
& \operatorname{Pr}\left(S_{t}=j, S_{t-1}=i \mid I_{t}, \theta\right)=\frac{f\left(y_{t}, S_{t}=j, S_{t-1}=i \mid I_{t-1}, \theta\right)}{f\left(y_{t} \mid I_{t-1}, \theta\right)} \\
& =\frac{f\left(y_{t} \mid S_{t}=j, S_{t-1}=i, I_{t-1}, \theta\right) \times \operatorname{Pr}\left(S_{t}=j, S_{t-1}=i \mid I_{t-1}, \theta\right)}{f\left(y_{t} \mid I_{t-1}, \theta\right)} \\
& f\left(y_{t} \mid S_{t}=j, S_{t-1}=i, I_{t-1}, \theta\right)=(2 \pi)^{-N / 2}\left|H_{t \mid t-1}^{(j, i)}\right|^{-1 / 2} \\
& \times \exp \left\{-\frac{1}{2}\left(y_{t}-B \alpha_{t \mid t-1}^{(j, i)}\right)^{\prime}\left(H_{t \mid t-1}^{(j, i)}\right)^{-1}\left(y_{t}-B \alpha_{t \mid t-1}^{(j, i)}\right)\right\} \\
& \operatorname{Pr}\left(S=j, S_{t-1}=i \mid I_{t-1}, \theta\right)=\operatorname{Pr}\left(S_{t}=j \mid S_{t-1}=i, \theta\right) \times \operatorname{Pr}\left(S_{t-1}=i \mid I_{t-1}, \theta\right) \\
& f\left(y_{t} \mid I_{t-1}, \theta\right)=\sum_{j=0}^{1} \sum_{i=0}^{1} f\left(y_{t}, S_{t}=j, S_{t-1}=i \mid I_{t-1}, \theta\right),
\end{aligned}
$$

When $\operatorname{Pr}\left(S_{t-1}=i \mid I_{t-1}, \theta\right)$ is given, every term in equation (19) is known, due to the Markovian assumption on $S_{t}$. Thus, for any given value of $\theta$, the associated filtered probability $\operatorname{Pr}\left(S_{t}=j \mid I_{t}\right)$ can be computed recursively through equations (18) to (22).

The recursion is initialized with the steady state probability of being in state $j \in\{0 ; 1\}$ at time $t=0$ :

$$
\begin{gathered}
\operatorname{Pr}\left(S=1 \mid I_{0}, \theta\right)=\frac{1-p_{0}}{2-p_{0}-p_{1}}, \\
\operatorname{Pr}\left(S_{0}=0 \mid I_{0}, \theta\right)=1-\operatorname{Pr}\left(S_{0}=1 \mid I_{0}, \theta\right)
\end{gathered}
$$

The previous formulas are also used to compute the loglikelihood function for the whole sample for any given value of $\theta$, since the loglikelihood function for the sample can be written as:

$$
\mathscr{L}(y, \theta)=\ln \left(f\left(y_{T}, y_{T-1}, \ldots, y_{0} \mid I_{T}, \theta\right)=\sum_{t=1}^{T} \ln \left(f\left(y_{t} \mid I_{t-1}, \theta\right)\right)\right.
$$

and $f\left(y_{t} \mid I_{t-1}, \theta\right)$ can be computed using formulas 18 to 22 .

The likelihood function can thus be maximized through a numerical optimization algorithm ${ }^{8}$. Then, if $\hat{\theta}$ is the maximum likelihood estimator of $\theta$, Kalman filter's formulas and Hamilton's filter can be used to compute the associated estimated factor and the associated filtered probabilities. In practice, the use of a numerical search algorithms appears to be relatively costly in terms of time and imposes limitations on the number of series included into the model. For instance, the

\footnotetext{
${ }^{8}$ For our estimations we used Nelder-Mead simplex direct search with maximum function evaluations set to 2000 , and tolerance for both function and dependent variables set to 0.001 . We set the initial values of the parameters to the estimates of the same state-space model but without switch, i.e. the estimates of Stock and Watson (1989) DFM. The latter is, in turn, initialized with the OLS estimates of the system of equations where the first principal component is used as a proxy for the latent common component.
} 
use of four classic series (industrial production index, employment, retail sales and real income of households) already implies estimation of 22 parameters. Every additional series brings at least four more coefficients to estimate, which extends the estimation time and increases the complexity of the optimal point search. For this reason, we'll mainly apply this method using four series, as it was done by Kim and Yoo (1995) and as it is often done in case of one-step estimation. We'll also assume that the transition probabilities are time-independent, and in most of the paper we'll assume that the switch happens in the constant only as described in (2).

Within this method it is thus assumed that the growth rate cycle of the economic activity is described as a common component of just a few series, so the choice of variables is essential and will be discussed in section 3 .

\subsection{Two-step estimation method}

As we just mentioned, the main drawback of the one-step method is that, due to computational constraints, it can only be used with a small set of data. Another possible approach is to proceed in two steps in the following way:

1. The factor $f_{t}$ is extracted from a large database of economic indicators according to equation (1) without taking its Markov-Switching dynamics into account. In the present paper, we use principal component analysis and we consider that the first principal component $\hat{f}_{t}$ gives a good approximation of the factor.

2. The parameters of the autoregressive Markov-Switching model described by equations (2) and (3) are estimated by maximum likelihood, with $f_{t}$ replaced by $\hat{f}_{t}$. This amounts to fit the univariate model of Hamilton (1989) to the estimated factor $\hat{f}_{t}$, which is taken as if it were an observed variable. The filtered probability of recession $\operatorname{Pr}\left(S_{t}=1 \mid I_{t},\right)$ is then calculated as in (18).

Let us recall that if a Markov switching model is estimated with Hamilton's method for an observable variable, say $z_{t}$, then the log-likelihood

$$
\ln f\left(z_{T}, z_{T-1}, \ldots, z_{0} \mid I_{T}, \theta\right)=\sum_{t=1}^{T} \ln f\left(z_{t} \mid I_{t-1}, \theta\right)
$$

is computed along the same lines as in equations (18)-(22) and has to be maximized through a numerical optimization algorithm too. However, as the number of parameters which have to be estimated is small in this case, the maximization of the loglikelihood through a numerical procedure does not raise any specific problem. This is one of the reasons why the two-step procedure is attractive: in the second step, the number of parameters which have to be estimated is small.

Another attractive feature of the two-steps procedure is that it allows to consider a large amount of series, which are used to build the estimated factors in the first step. Here we take the first principal component of 151 economic indicators concerning the production sector, financial sector, employment, households, banking system, international trade, monetary indicators, major world economic indicators, business surveys and others. This large set of series is more likely to reflect the business cycle than a small set of series, as it is used in the one-step procedure (as we said 
before, many authors use only 4 series when they want to estimate this kind of model).

Finally, as the second step of the two-step procedure is easily tractable, it is possible to introduce additional switching parameters, and to estimate, this way, richer models. For instance, it is possible to consider a switching variance and to replace $\sigma_{\eta}^{2}$ with $\sigma_{\eta_{S_{t}}}^{2}$.

The two-step procedure has been employed in several papers (see the non exhaustive list given in the introduction) but in most of them, the number of series under study is small or moderate. Further, Camacho et al. (2012) argue that this two-steps procedure faces misspecification problems, since the Markov-switching dynamics are not taken into account in the first step. We think that, under standard assumptions, the two-steps procedure gives in fact consistent estimators of the parameters. The complete proof of this consistency is addressed in a companion paper (which is still in progress at this time), but the main idea is that, under these standard assumptions, the first principal component consistently estimates the factor. Indeed, as $\left(S_{t}\right)$ is supposed to be a stationary ergodic Markov chain, $\left(f_{t}\right)$ is a stationary process and all the usual sets of assumptions which are commonly used to assert the consistency of PCA for large $N$ and large $T$ (see Bai (2003), Stock and Watson (2002) for instance) can be employed in the present setting.

To conclude this section, let us also mention that PCA is not the only way to get a consistent estimator of the factor in the first step. In future work, we intend to extract the factor on the first step either with the two-step estimator based on Kalman filtering which has been proposed by Doz et al. (2011) or with the QML estimator (Doz et al. (2012)). It seems indeed promising to use these two methods in the first step of the present framework, as they may provide more efficient estimators and as they allow for mixed frequency, missing data, and data with ragged ends.

\section{Data, reference dating and quality indicators}

\subsection{The dataset}

For the purpose of comparison one would like to run the two estimation methods on the same dataset. However due to the different requirements on the number of series in the database for each method (large dataset for the two-step method in order to get the consistency of the PCA factor estimate, small dataset for the one-step method to obtain the convergence of the algorithm), we are unable to perform this kind of analysis. We therefore use a separate dataset for each method.

The database for the two-step procedure is constructed on the basis similar to the databases by Stock and Watson (2010) for the US and Bessec and Doz (2012) for France. It contains 151 monthly series spanning the period May 1993 - March $2014^{9}$. The data covers the information on production sector, financial sector, employment, households, banking system, business surveys, international trade, monetary indicators, major world economic indicators and other indicators.

\footnotetext{
${ }^{9}$ The trade-off between the sample size and the number of cross-sections made us restrict the dataset to just 21 years of observations. A longer period (starting with 1990) would reduce the number of cross-sections to 97, while the full original balanced database (213 series) starts in February 1996.
} 
For the one-step method it is crucial to select series properly. The series must be an indicator of the economic cycle and should be available in monthly frequency. We choose 25 series out of the 151 series of the database for the two-step method and to use them in combinations by four, overall $C_{25}^{4}=12650$ combinations. The strategy of trying all possible combinations by 4 out of 25 may seem too bulky and inelegant, however we deliberately avoided any data selection technique in order to minimize its possible impact on the output of the one-step results. The selection was made on the basis of existing literature on one-step method applied to business cycle analysis. To the four classical indicators for business cycle dating of the US economy (total personal income, total manufacturing and trade sales, number of employees on nonagricultural payrolls, total industrial production index) we added series used in Kholodilin (2006) (French stock market index CAC40, interest rates on the 3 months and 12 months government bonds, imports and exports), selected series of business surveys, proved to be useful by Bessec and Doz (2013), the components of the OECD Composite Leading Indicator, as well as several series characterizing the dynamics of the major trade partners (Germany, the USA, Asia). Since almost all of these series have been already used in the analysis of the French business cycle (and the others are likely to comove with it), we suppose that the common component of each combination can be considered as an estimate of the business cycle.

All series are seasonally adjusted, tested for the presence of unit root and taken in differences if it is present, then centralized and normalized. Detailed lists of series for both methods are given in Tables A.1 and A.2 of Appendix A.

\subsection{Reference dating}

In order to measure the quality of the results of each of the two methods, we need to compare it to some reference business cycle chronology. The choice is not obvious, as the true dating is unknown, whereas the estimates of the true dating provide different sets of turning points. To our knowledge, there are at least three open source dating chronologies for the European countries: $\mathrm{OECD}^{10}, \mathrm{CEPR}^{11}$ and ECRI ${ }^{12}$. Note that INSEE does not publish any official business cycle dating. Figure 1 below shows that these chronologies indeed do not coincide in the starting and the final points of recessions and in the duration of economic cycle phases. Moreover, OECD detects a recession of April 1995 - January 1997 which other institutions do not identify.

The difference obviously lies in the methodology and the data taken into consideration. The OECD dating is the output of the Bry-Boschan algorithm applied to the Composite Leading Indicator (CLI), which is an aggregate of a fixed set of 9 series $^{13}$, highly correlated to the reference series (industrial production index or GDP series). The turning point chronologies of CEPR are

\footnotetext{
${ }^{10}$ http://stats.oecd.org/mei/default.asp?rev $=2$

${ }^{11} \mathrm{http:} / /$ www.cepr.org/content/euro-area-business-cycle-dating-committee

12 https://www.businesscycle.com/

${ }^{13}$ The CLI components are: 1. New passenger car registrations (number) 2. Consumer confidence indicator (\% balance) 3. Production (Manufacturing): future tendency (\% balance) 4. SBF 250 share price index (2010=100) 5. CPI Harmonized All items $(2010=100)$ inverted 6. Export order books (Manufacturing): level (\% balance) 7. Selling prices (Construction): future tendency (\% balance) 8. Permits issued for dwellings $(2010=100)$ 9. Expected level of life in France (Consumer Survey) (\% balance). All series are detrended, and seasonally, calendar- and noise-adjusted. They are selected so that they have a cycle pattern similar and coincident (or leading) to the one of the reference series. Until April 2012 the industrial production index was taken as a reference series, replaced by monthly estimates of GDP growth afterwards.
} 
Figure 1: Economic cycles chronologies according to OECD, ECRI and CEPR. The recession phase corresponds to 1 , the expansion phase corresponds to 0 .

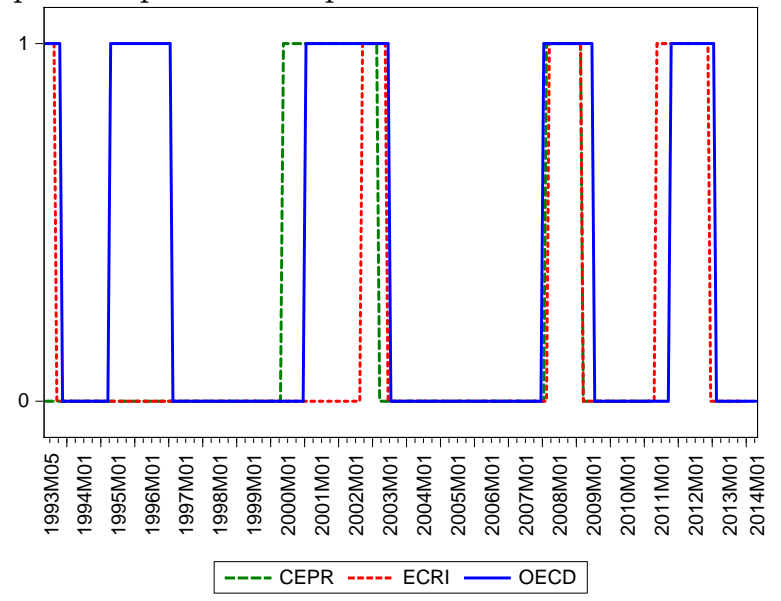

obtained from the balance of expert opinions on the basis of series selected by the experts involved. The ECRI index is the output of an undisclosed statistical tool on the undisclosed (but probably the most information-rich) dataset.

In this paper we take the OECD dating as a benchmark as it relies on a clear and replicable algorithm. Therefore, the time sample that we consider covers 5 crises in the French economy as determined by OECD (see Figure 2):

Figure 2: OECD reference turning points for the French economy, 1993-2013

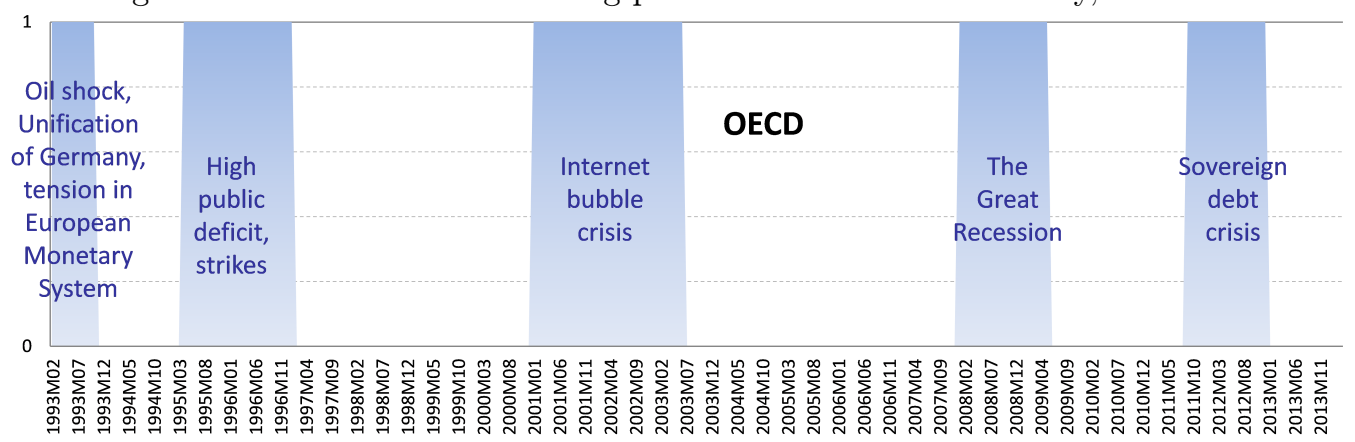

Note: 1 corresponds to recession, 0 - to expansion

- March 1992 - October 1993: the crisis, caused by the oil shock following the first Gulf War, German reunification and tensions in European Monetary system;

- April 1995 - January 1997: rather a slowdown in economic growth rates than a real recession, with 
only one quarter of slightly negative $(-0.011)$ growth rate, caused by the decrease of high public deficit and the consequent strikes throughout the country;

- January 2001 - June 2003: the Internet bubble crisis;

- January 2008 - June 2009: the Great Recession, the global financial crisis;

- October 2011 - January 2013: the sovereign debt crisis.

It can be argued that OECD dating can not be used as a reference because it represents the chronologies of the growth cycle, whereas we use MS-DFM to identify the growth rate cycle (for most series, in order to achieve stationarity in data we use differences of logarithms). In our exercise, we avoid cyclical component extraction on purpose as it implies additional complications inherent to the definition of a trend. However, we support our choice by the fact that the OECD chronology is the closest to the other cyclical indicators calculated for France. In the working paper by Bardaji et al. (2008) (and in a similar paper Bardaji et al. (2009)), the authors propose a reference dating on the basis of the cyclical component of GDP extracted with Christiano-Fitzgerald filter. We reproduce these estimates on the basis of monthly interpolated GDP growth data. The dating we obtain is indeed very close to OECD results. In the same time, it is rather close to the dating obtained by Anas et al. (2007) for Eurostat (see Figure 3).

Note that the dating on the basis of Christiano-Fitzgerald filter has two additional recessions (in 1998-1999 and 2004-2005) which are not present in the OECD dating. Interestingly, the Reversal Index ${ }^{14}$ also detects these additional recessions, having spikes of high probability of recession in 1998 and 2005 (see Figure 4). This discrepancy might be due to an important feature of the Bry-Boschan procedure which is the existence of a lower bound of phase duration (15 months). Consequently, short recessions or expansions do not appear in the OECD chronology.

\footnotetext{
${ }^{14}$ The Reversal Index (l'Indicateur de Retournement) published by INSEE is the index comprised between -1 and 1 which shows the difference between the probability to be in expansion in the current period and the probability to be in recession in the current period. The index is based on the business surveys about the current, past and future perceptions of the economic situation.
} 
Figure 3: Turning point chronology of the French economy

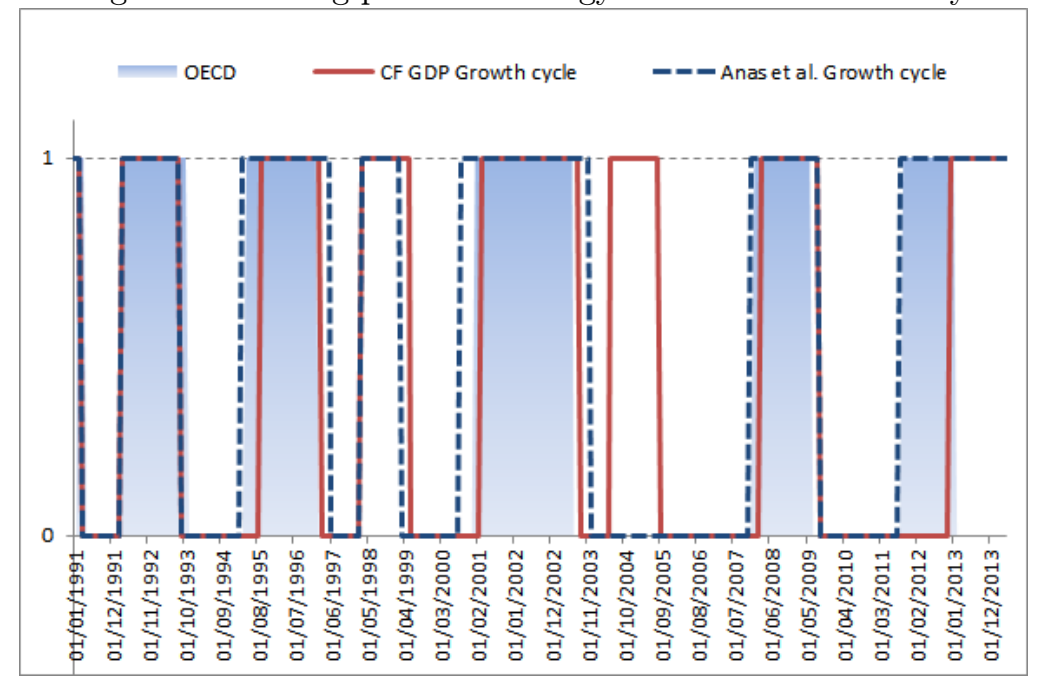

Note: Shaded areas correspond to the OECD dating, the blue dashed line corresponds to the dating for the French economy produced for Eurostat by Anas et al. (2007), the red solid line corresponds to the GDP growth cycle extracted with Christiano-Fitzgerald filter. 1 to recession, while 0 corresponds to expansion. A Christiano-Fitzgerald filter is applied to the series of French GDP in levels (bandwidth 6 to 40 quarters), the turning points are considered to take place in the second month of a quarter.

Figure 4: The index of reversal (solid blue line, right axis) and OECD reference dating (shaded areas, left axis)

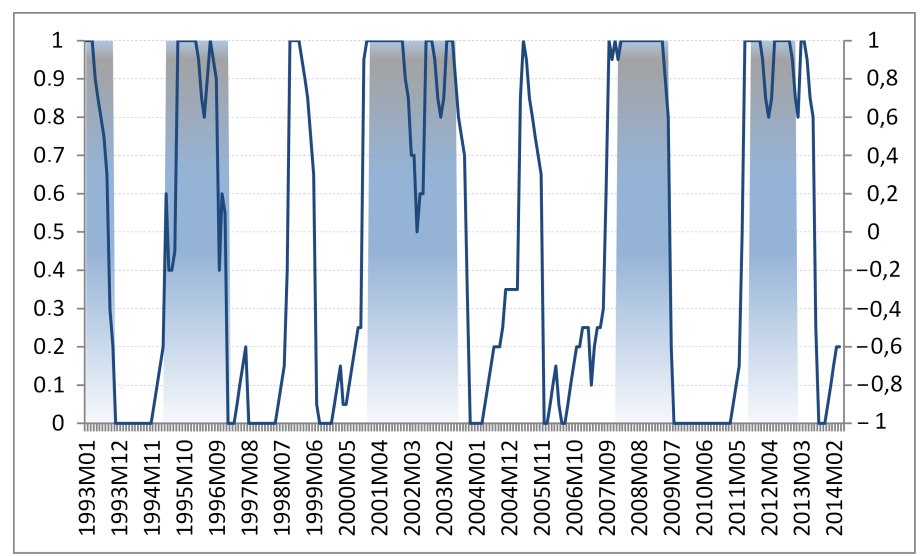

Indeed, in both cases INSEE detected a temporary deterioration of the economic activity due to different reasons. In 1998-1999 France experienced a significant decline in the net external trade. Undermined by the Asian and Russian crises, the external demand from Japan, China and Russia, as well as other developing Asian countries and even the UK, Belgium, Italy, fell dramatically - 
from $10 \%$ growth rate in 1997 to only $4 \%$ in 1998. The depreciation of yen and dollar contributed to the appreciation of the real effective exchange rate of franc. In general, the external balance of France decreased by $7.1 \%$ which resulted into negative contribution to the GDP growth (-0.4 pp $)^{15}$. The producers were pessimistic about future activity (also worried about the financial crisis and reducing prices for energy and oil which threatened to turn into disinflation), decreasing their investment and limiting the inventories ${ }^{16}$. In 2005 the external demand of France decelerated substantially due to uncertainty in the economic situation in the US and Japan caused by the oil price shock. Producers in manufacturing and service acted with caution: the prices for raw materials were rising, and euro was appreciating in real terms, the saving rate of households fell, the GDP quarterly growth was declining, too ${ }^{1718}$.

To summarize, the OECD dating largely coincides with the other existing cyclical indicators for the major recessions, however some other indicators may detect additional shorter recession episodes.

\subsection{Measures of quality}

To assess the quality of the results of each of the two methods we use the three following indicators:

- Quadratic probability score. This indicator shows the average error of filtered probability as an average quadratic deviation from the reference dating. The higher $Q P S$ is, the lower is the quality of fit.

$$
Q P S=\frac{1}{T} \sum_{t=1}^{T}\left(R D_{t}-\operatorname{Pr}\left(S_{t}=1 \mid I_{t}\right)\right)^{2}
$$

where $T$ is the number of periods in the sample, $R D_{t}$ is the reference dating series of 0 and 1 ( 1 corresponding to recession, 0 to expansion), and $\operatorname{Pr}\left(S_{t}=1 \mid I_{t}\right)$ is the filtered probability of being in recession in period $t$.

- False positives. This indicator counts the number of wrongly predicted periods. Here we set the threshold probability on the intuitive level of 0.5 .

$$
F P S=\sum_{t=1}^{T}\left(R D_{t}-I_{P r\left(S_{t=1} \mid I_{t}\right)>0.5}\right)^{2}
$$

where $I_{\operatorname{Pr}\left(S_{t=1} \mid I_{t}\right)>0.5}$ is the indicator function equal to 1 if the estimated filtered probability if higher than 0.5 (determines recession) and 0 otherwise. The lower FPS is, the more qualitatively accurate is the model.

- Correlation. An accurately estimated filtered probability should have a high correlation with the reference dating. We use a simple sample correlation Corr between the two series.

\footnotetext{
${ }^{15}$ INSEE PREMIERE, N659 - June 1999

${ }^{16}$ INSEE CONJONCTURE, Note de conjoncture, December 1998

${ }^{17}$ INSEE CONJONCTURE, Note de conjoncture, Mars 2005

${ }^{18}$ Interestingly, Bruno and Otranto (2004) also find similar signals of 1998-1999 and 2005 for the chronology of the Italian economic cycle.
} 


\section{Estimation results}

\subsection{One-step method}

\section{Informative series}

The estimation over 12650 combinations did not produce 12650 outputs as for most of the combinations the convergence was not achieved, or the series combination produced a factor that does not have a nonlinear structure. Therefore, only 575 combinations achieved convergence, and only 424 of them have interpretable filtered probabilities. Out of this number, we have retained 72 results that are informative in terms of signals of past recessions. Interestingly, the best candidate for the benchmark results - the combination of four series used by Kim and Yoo (1995), Kim (1994), Chauvet (1998) and others for business cycles of the US (total index of industrial production, employees in nonagricultural payrolls, total personal income less transfer payments, total manufacturing and trade) did not achieve convergence.

We construct the frequency rating of economic series (given in Table B.1 of Appendix B) for the integrity of all interpretable results of the one-step estimation. Some series turned out to have weak explanatory content, such as CPI index or CAC-40 financial index, the latter entering none of successful combinations. Others did much better: construction confidence indicator, capacity utilization, exports, retail trade confidence index and unemployment rate appear each in $22,21,20$ and 19 combinations, respectively. This allows us to suggest that the contribution of these indicators is important for the final aggregate factor to follow a bi-state dynamics. Interestingly, CPI and the stock market index both enter the OECD CLI, but they do not seem to be very informative for the turning points detection in our framework.

To illustrate the results that we considered as interpretable, we present the output of one of the plausible combinations on Figure 5. It consists of the 4 most frequent indicators that we mentioned above: unemployment rate, exports, retail trade and construction confidence indicator. The resulting filtered probability is one of the best in terms of fit to the OECD official dating.

As we can see from this figure, this combination produces a factor probability that captures 4 out of 5 crises if we consider the economy to be in recession if the filtered probability of a recession is higher than 0.5. One can notice two important features of this example: first, there is an extra signal in 2004; second, not all the crises are explained equally well. These pitfalls are often present in the other outcomes, so we discuss each of them in details.

\section{Extra signals}

In general, out of 72 combinations only 27 do not produce any extra signals of recession. The other 45 combinations give an additional alert in the end of 1998, or another one around mid-2005, or both. Among the series with the highest loadings that appear relatively more often in such combinations than in the other ones are manufacturing finished goods stocks level, price return on FTSE equity index and Manufacturing Industrial Confidence Indicator. Indeed, we can see that 
Figure 5: The result of 1step estimation on unemployment rate, exports, retail trade and construction confidence indicator: the filtered probability of recession (blue line) and the reference dating (shaded area, OECD, 1 corresponds to recession state).

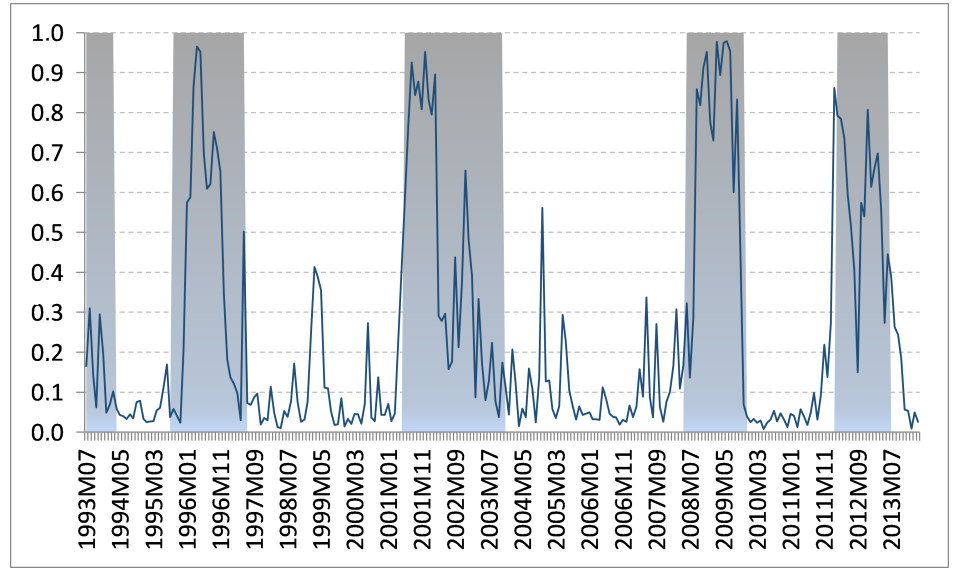

all three series underwent significant downturn in 1998-1999, while in 2005 stocks of manufacturing finished goods and manufacturing confidence index fell back to the levels of the end of the Internet bubble crisis (see Figure 6). However, these events are not captured by the OECD dating.

As we have mentioned above, these signals are not misleading in the sense of producing a false alert of recession when the economy is actually growing, and they correspond to a real deterioration of economic conditions. However, for the closest match to the OECD reference, these signals should be avoided. The one-step approach allows to do so, since one can exclude the series that are likely to produce extra signals from the dataset.

\section{Different set of series for different crises}

As for OECD detected recessions, it is important to keep in mind that none of them (at least the 5 recessions we consider here) had the same origins as the other, so it is possible that the determinants of economic activity evolved with time, and so it is likely that the common factor of a particular set of series does not perceive the Great recession as well as it reflected the crisis of 1992-1993. However, in order to construct a universal instrument, it is preferable to find series that would capture the recession in all cases, if possible. For this purpose we compare the quality indicators of 72 sets of variables for each crisis separately. The Table B.2 in Appendix B summarizes the information on the best combinations by crisis. Here FPS shows the proportion of months of each crisis incorrectly determined as expansion, i.e. the lower FPS is, the better a crisis is captured.

We can see that:

- the combination consisting of volume of total retail trade, unemployment rate, trade balance and order books in the building industry, with the highest loadings on unemployment, is the best to detect the first and the last crisis and captures the second crisis well, too; 
Figure 6: False signals suspects

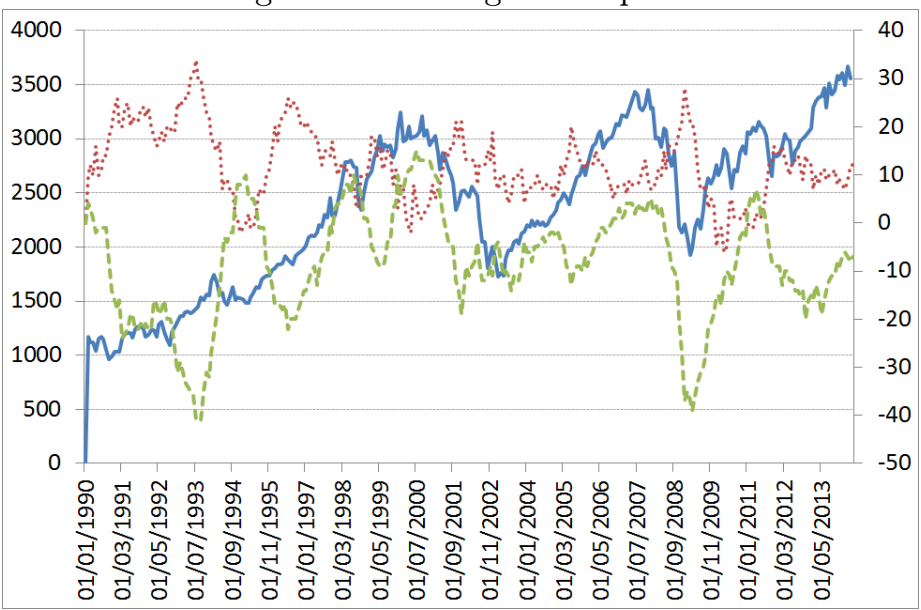

FTSE 100, All-Share, Index, Price Return, End of Period, GBP (solid line, left axis), Manufacturing Finished Goods

Stocks Level (dotted line, right axis), Manufacturing Industrial Confidence Indicator (dashed line, right axis)

- the combination consisting of new passenger cars sales and registration, retail trade orders intentions, export, confidence indicator in services, with the highest loadings on retail trade and Confidence Index in services, is leading in case of the second, the third and the fourth crises, being significantly superior to the other combinations for the third and the fourth recessions;

- although good on certain periods of the timeline, unfortunately none of these sets of variables could be used as a 'core' set due to their relatively poor performance on the expansion periods and non-detected crises.

The set of data contained in these 2 combinations appears to be sufficient to identify all 5 crises with a special role given to unemployment, retail trade orders intentions and confidence index in services.

\section{The finally selected information set}

Considering the observations on the effects of different series on the final filtered probability, we conclude that a good information set (relative to OECD reference) would:

1) contain the series that determine all the 5 crises,

2) not contain the series that produce extra signals,

3 ) perform well in general in terms of $Q P S, F P S$ and Corr.

The top 25 combinations with the lowest $Q P S$ and $F P S$ measures and the highest Corr are given in Table B.3 in Appendix B. The first eight are in the best $10 \%$ by all three indicators, so 7 of them (we exclude the second combination because of the presence of extra signals) could be candidates for the core sets of economic indicators that enable to match closely the OECD dating. The graphs of corresponding 7 filtered probabilities are given in Figure B.1 of Appendix B. 
It is not surprising that there are several "best" sets of variables, as the restriction of the model to comprise only 4 series into the model is just a technical limitation, and the factor matching the dynamics of the economic activity is determined by much more series. The analysis of the factor loadings of these 7 combinations can give us an idea of the economic indicators that play the most important role. According to our estimations, the heaviest factor loadings belong to (see Table B.3 in Appendix B):

- France, OECD MEI (Enquete de Conjoncture INSEE), Retail Trade Orders Intentions, SA;

- France, INSEE, Metropolitan, Unemployment, Job Seekers, Men, Total, Categories A, B \& C, Calendar Adjusted, SA

- France, OECD MEI (Enquete de Conjoncture INSEE), Manufacturing Business Situation Future, SA

- France, Business Surveys, DG ECFIN, Construction Confidence Indicator, Balance, SA

The first two of these indicators were also determined as components of the Growth Cycle Coincident indicator by Anas et al. (2008).

Among the other indicators contributing to the factors in the 7 selected combinations are:

- France, Consumer Surveys, INSEE, Consumer Confidence Indicator, Synthetic Index, SA

- France, INSEE, Domestic Trade, Vehicle Sales \& Registrations, New, Passenger Cars, Total, Calendar Adjusted, SA

- France, OECD MEI, INSEE, Total Retail Trade (Volume), SA, Change P/P

- France, OECD MEI, INSEE, Manufacturing Finished Goods Stocks Level, SA

- France, INSEE, Foreign Trade, Trade Balance, Calendar Adjusted, SA, EUR

- France, INSEE, Foreign Trade, Export, Calendar Adjusted, SA, EUR

- Japan, Economic Sentiment Surveys, ZEW, Financial Market Report, Stock Market, Nikkei 225, Balance

— United States, Equity Indices, S\&P, 500, Index (Shiller), Cyclically Adjusted P/E Ratio (CAPE)

- France, Service Surveys, DG ECFIN, Services Confidence Indicator, Balance, SA

As an output of this analysis we have thus retained 13 out of 25 series which can be considered as essentially informative of the French business cycle. We tried to use the one-step method on these 13 series simultaneously, in order to take into account all the main information. Unfortunately, the optimization algorithm did not achieve convergence while searching for likelihood maximizing set of parameters, although, with the parameters set on their initial values, the filtered probability calculated at the initial values of parameters (obtained with OLS) captures all the five crises without detecting any extra recessions, as expected (see Figure B.2 in Appendix B). Therefore, since it seems unfeasible to use the information contained in the above listed 13 series simultaneously within onestep approach, the results of the 7 combinations could be used as complements.

\subsection{Two-step method}

\section{First step: PCA}

On the first step of the procedure we extract the first factor by principal component analysis. The first principal component that we use as a proxy for the factor in the two-step method describes 
$23.43 \%$ of the total variance which is quite reasonable when considering the size and heterogeneity of the database. The dynamics of the first component and the factor loadings are presented below in Figure 7 and Figure 8. One can note that it is close to the dynamics of GDP growth, so the factor is relevant. Indeed, the correlation on the whole sample is equal to 0.91 , while the correlation on the shorter period ending in December 2007 to eliminate the impact of the Great Recession is 0.895 .

Figure 7: First principal component and monthly GDP growth rate

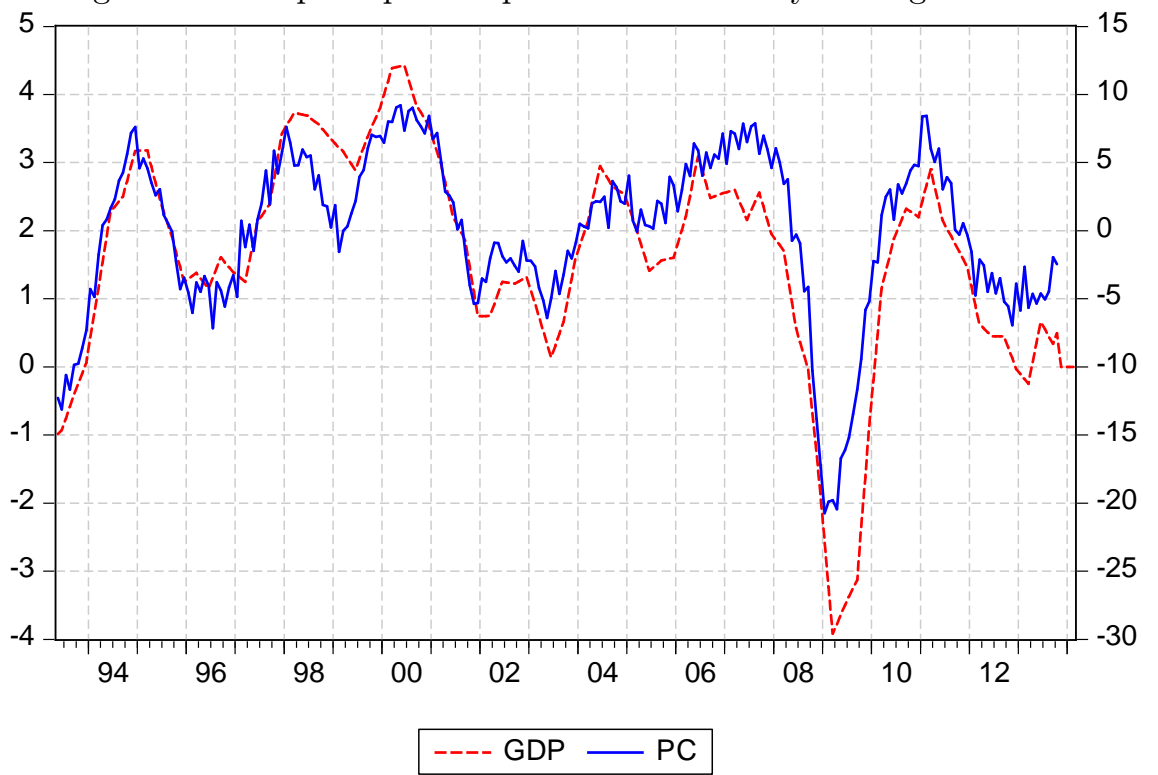

Note: the solid blue line corresponds to the dynamics of the first principal component of the full dataset (left axis), the dashed red line corresponds to the French GDP growth series (left axis). The quarterly GDP growth series were converted into monthly series via linear interpolation. 
Figure 8: Factor loadings corresponding to the first principal component

\section{LOADINGS}

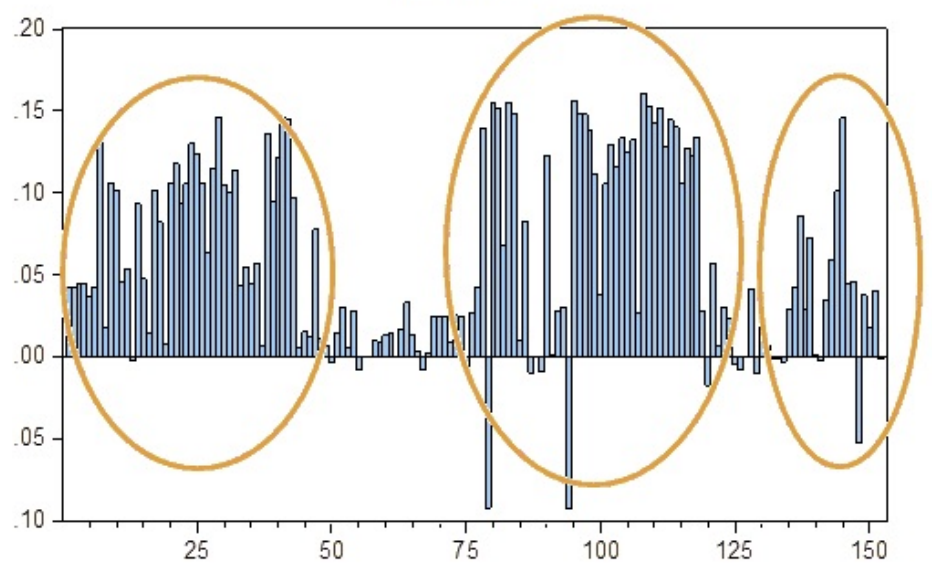

The three groups of highest loadings of the first component correspond to (in circles, from left to right): 1) production and

consumption series, disaggregated; 2) business surveys; 3) series on the world economy.

The three groups with the highest loadings corresponding to the first component belong to: 1) production and consumption series, disaggregated; 2) business surveys; 3) series concerning the world economy. The first component therefore captures the present behavior of firms and households (including their expectations about the short-term future) and the impact of foreign economies and pays less attention to the banking and financial sector, monetary aggregates, balance of payments and currency indicators.

\section{Second step: estimation of a Markov-Switching model}

\section{Basic specification, switch in mean.}

On the second step of the two-step estimation procedure we estimate a Markov-switching model as defined in equation (2), with the unobservable factor replaced by the first principal component estimated on the first step ${ }^{19}$. The results are quite satisfactory, with the filtered probabilities capturing all the crises well (but the first one) and without sizable leads and lags (see Figure 9). As expected, the estimations provide a positive constant for the expansion periods, and a negative one for recessions: $\mu_{0}=1.04, \mu_{1}=-1.77$, respectively (the estimates are significant at $1 \%$ level of significance). For this specification, $Q P S=0.1278, F P S / T=0.1872, C o r r=0.75$, and the average lag of the identification of the beginning of recession is 0.75 months, while the end of recession is detected 1 month earlier. Note that this result is comparable to the average result of our one-step estimations $(Q P S=0.1346, F P S / T=0.1779$, Corr $=0.69)$.

\footnotetext{
${ }^{19}$ Following Kim and Yoo (1995), we put 2 autoregressive lags in the baseline specification. This assumption turned out to be plausible: the correlogram of the first principal component has high partial autocorrelation for the first two lags. The choice of two lags was also confirmed with the values of Akaike and Schwarz information criteria estimated on the model with one, two and three autoregressive lags.
} 
Figure 9: Filtered probability of recession, the two-step estimation (switches in constant, nonswitching autoregressive coefficients and variance), OECD reference dating (shaded areas)

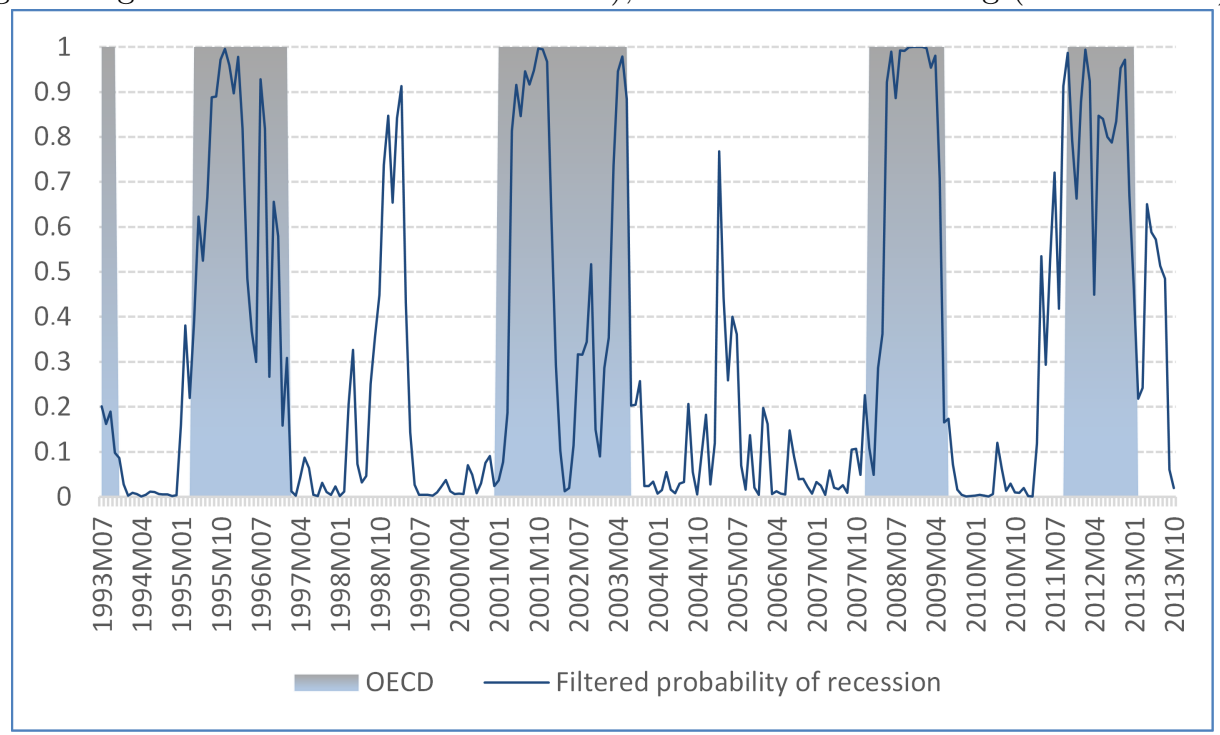

The extra signals of 1998-1999 and 2004-2005 are clearly detected by the first component. This may be explained by the fact that the dataset includes the series which induce extra signals for the one-step method, as well as a number of other series that experienced shocks in these periods. We did a simple exercise by trying to eliminate these series from the dataset. It turned out impossible to get rid of all extra signals without deteriorating the signals on the OECD recessions. The removal of series undermines the performance of the two-step method and deprives it of its most valuable advantage - the large scale of dataset.

Besides extra signals of 1998 and 2005, we can observe a transitory improvement in the middle of the Internet bubble crisis and the earlier detection of the beginning of the sovereign debt crisis, also omitted by OECD. Similarly, the reasons for this amelioration can be tracked in the INSEE reports ${ }^{20}$.

\section{Alternative specification, switches in mean and variance.}

We take advantage of the possibility to introduce switches into other coefficients of the model to check whether it will bring to enhanced detection of the turning points. Now we let the variance

\footnotetext{
${ }^{20}$ INSEE observed the enhancement of the business climate in 2001 primarily due to the subjective perception that the US have passed the trough of the business cycle, rebound growth in Asia, Germany and the negative oil price shock improved the expectations of investors and entrepreneurs, while the decrease in taxes gave an extra stimulus for household consumption, increasing their purchasing power (INSEE CONJONCTURE, Note de conjoncture, Mars 2002). The reasons for early peaks in 2011 are the deterioration of business climate in France, seism in Japan, antiinflation policies in developing countries, as well as budget consolidation policy in the developed countries, positive price shocks for commodities (oil included) increased production costs. All this led to a certain pessimism among French investors (Point de conjuncture October 2011, INSEE).
} 
of the error term in the factor dynamics to be state specific, too, so the model of factor dynamics becomes:

$$
f_{t}=\beta_{S_{t}}+\phi_{1} f_{t-1}+\phi_{2} f_{t-2}+\eta_{S_{t}}
$$

where $\eta_{s_{t}} \sim N\left(0, \sigma_{S_{t}}^{2}\right)$. While on average as performative $(Q P S=0.1278, F P S / T=0.1885$, Corr $=0.67)$ as the basic specification, the alternative specification is slightly better in capturing the beginnings and ends of recessions (the identification lag is 0 and 1 months on average, respectively ${ }^{21}$. As before, the estimations provide a positive constant for the expansion period, and a negative one for recessions $\mu_{0}=1.22, \mu_{1}=-1.52$. The volatility of the factor dynamics is estimated to be almost two times higher during recessions $\left(\sigma_{0}=0.4, \sigma_{1}=0.75\right)$. The estimates of the other parameters are given in Table C.1 in Appendix C. Again, the filtered probabilities produced by this specification capture all the crises well (but the first one) and without sizable leads and lags. The dynamics of filtered probabilities for this specification resembles the one for the basic specification, so we do not report the graph here.

\subsection{Comparison: one-step vs two-step}

We compare the average performance of the one-step method and the two-step method in the baseline specification (lines "One-step method, average" and "Two-step method, full dataset" in Table 1). The difference in QPS and FPS is negligible $(Q P S=0.13, F P S / T=0.18$ for the average one-step method versus $Q P S=0.13, F P S=0.19$ for the two-step method), whereas the correlation with the OECD dating is only slightly higher for the one-step method $(C o r r=0.69$ versus $C o r r=0.67)$. So, on average it is difficult to put forward the performance of one or another method. However, taking into account that the extra signals are responsible for part of the QPS and FPS/T of the two-step method, the two-step method is more precise in detecting OECD recessions. In particular, the two-step method is much more accurate with respect to the beginning and the end of recessions, with a tendency to indicate the beginning of a recession on average one quarter of a month earlier; the one-step method is late with the beginning on 2.5 months and precipitates the end by 2.6 months, on average. In general, both methods produce early estimates: for the one-step method the data in each of the retained combinations are updated with 1 month or even 0 month lag. This means that the phase of the business cycle in January can be determined either in February or March, with no need to wait for the release of quarterly OECD dating in April. Though the gain in time is not very big, it may still be of a great important for policy makers. For the two-step method, the estimates are available in two months, which is still less than the timing of OECD. In this respect, the estimation of the factor on the first step with the help of one of the procedures proposed by Doz et al. $(2011,2012)$ is very promising since it allows to have the estimator of the factor on the available information only, without waiting until all series in the database are updated. We leave this exercise for further research.

As for the parameter estimates, the two methods give qualitatively similar results in terms of values of coefficients (see Table C.1 in Appendix C): there are two distinct regimes, which are characterized by a negative constant in the recession state and a positive constant in the expansion state.

\footnotetext{
${ }^{21}$ We also tried specifications with switching autoregressive coefficients and different combinations of switching parameters, but none of them are as performative. To save space, we do not report the results here.
} 
Table 1: The comparison of one-step and two-step estimation results

\begin{tabular}{|c|c|c|c|c|c|c|}
\hline & QPS & $\mathrm{FPS} / \mathrm{T}$ & Corr & Start lag & End lag & Timing \\
\hline \multicolumn{7}{|l|}{ Benchmark Hamilton univariate MS-AR model } \\
\hline Hamilton's AR-MS on IIP (benchmark) & 0.3679 & 0.5231 & 0.0894 & $\infty$ & $\infty$ & $0 \mathrm{M}$ \\
\hline \multicolumn{7}{|l|}{ MS-DFM (Kim and Yoo (1995)) } \\
\hline One-step method, average & 0.1346 & 0.1779 & 0.6985 & 2.5 & -2.6 & $1 \mathrm{M}$ \\
\hline One-step, combination 1 & 0.1287 & 0.1383 & 0.7155 & 0.6 & 0.4 & $1 \mathrm{M}$ \\
\hline One-step, combination 2 & 0.1254 & 0.1779 & 0.6899 & 1.8 & -0.2 & $1 \mathrm{M}$ \\
\hline One-step, combination 3 & 0.1328 & 0.1818 & 0.7431 & 3.4 & -3.8 & $0 \mathrm{M}$ \\
\hline One-step, combination 4 & 0.1412 & 0.1818 & 0.7006 & 5.2 & -4.2 & $1 \mathrm{M}$ \\
\hline One-step, combination 5 & 0.1184 & 0.1858 & 0.7082 & 3.6 & -3.6 & $1 \mathrm{M}$ \\
\hline One-step, combination 6 & 0.1493 & 0.1937 & 0.6815 & 3 & -8 & $1 \mathrm{M}$ \\
\hline One-step, combination 7 & 0.1492 & 0.1976 & 0.5607 & 1.8 & 0.6 & $1 \mathrm{M}$ \\
\hline Two-step method on 13 series & 0.3259 & 0.3287 & 0.1649 & $\infty$ & $\infty$ & $1 \mathrm{M}$ \\
\hline Two-step method on 25 series & 0.1207 & 0.2083 & 0.5703 & 2.5 & -0.5 & $1 \mathrm{M}$ \\
\hline Two-step method, full dataset & 0.1315 & 0.1926 & 0.6712 & 0.75 & -1 & $2 \mathrm{M}$ \\
\hline \multicolumn{7}{|l|}{ Other specifications of MS-DFM } \\
\hline Two-step method, full dataset, switching $\sigma^{2}$ & 0.0737 & 0.1885 & 0.6724 & 0 & 1 & $2 \mathrm{M}$ \\
\hline Two-step method, switching $\mu$ and $\sigma^{2}, \operatorname{MS}-\operatorname{AR}(4)$ & 0.0658 & 0.1762 & 0.6751 & 0 & 0.8 & $2 \mathrm{M}$ \\
\hline Two-step method, switching $\mu$ and $\sigma^{2}+$ pc2 & 0.2495 & 0.3648 & 0.3953 & $\infty$ & $\infty$ & $2 \mathrm{M}$ \\
\hline Two-step method, switching $\mu$ and + pc4 & 0.1027 & 0.1803 & 0.6602 & 1.75 & -1.75 & $2 \mathrm{M}$ \\
\hline Two-step method, switching $\mu$ and $\sigma^{2}+$ pc 4 & 0.0699 & 0.1721 & 0.7058 & 2 & 0.75 & $2 \mathrm{M}$ \\
\hline \multicolumn{7}{|l|}{ Other results for the French economy } \\
\hline Kaufmann (2000) & - & 0.2151 & - & - & - & - \\
\hline Chauvet and Yu (2006) & - & 0.3777 & - & - & - & - \\
\hline Chen (2007) & - & 0.2839 & - & - & - & - \\
\hline Kholodilin (2006) & 0.152 & 0.3333 & - & - & - & - \\
\hline
\end{tabular}

For the composition of combination $i$ see Table B.3 and Table A.2. Start lag - the number of lags between the estimated beginning of a recession and the OECD determined beginning; End lag - the number of lags between the estimated end of a recession and the OECD determined end; $T$ is the number of periods in the sample 
The difference between the two constants varies in absolute value as the the magnitude of factors is either determined by the underlying economic indicators (for the one-step method) or is estimated up to a constant (in case of two-step method). The estimates of transition probabilities are similar, too: the phases of the French growth rate cycle are very persistent, with the probability to stay in expansion (on average, $p_{0}=0.96$ ) a bit higher than the probability to stay in recession (on average, $p_{1}=0.91$. All other estimates of the Table C.1 cannot be interpreted directly as they refer to different series and are given for information. The estimation of the model with both methods on expanding sample showed that the estimated coefficients and the resulting filtered probabilities are robust when the sample is up to 50 points shorter, however the convergence is not always achieved for the one-step method.

The comparison to the results in the preceding literature by Kaufmann (2006), Chauvet and $\mathrm{Yu}$ (2006), Chen (2007), Kholodilin (2006) shows the advantage of the MS-DFM in detecting the business cycle turning points, although it should be considered with care since we compare the results on slightly different (although overlapping) time spans.

The final datings for both methods are similar in general, although some incoherence and divergence from the OECD series exists (see Table 2).

Table 2: Final dating produced by one-step procedure on 7 best sets of data, two-step procedure and OECD dating

\begin{tabular}{|c|c|c|c|c|c|c|c|c|c|c|}
\hline & & Comb 1 & Comb 2 & Comb 3 & Comb 4 & Comb 5 & Comb 6 & Comb 7 & 2 step & OECD \\
\hline \multirow{2}{*}{ 1st crisis } & $\mathrm{P}$ & & & & & & & $1993 \mathrm{mo2}$ & & $1992 \mathrm{m02}$ \\
\hline & $\mathrm{T}$ & & & & & & & $1993 \mathrm{~m} 10$ & & $1993 \mathrm{~m} 10$ \\
\hline \multirow{2}{*}{ 2nd crisis } & $\mathrm{P}$ & $1995 \mathrm{m07}$ & $1995 \mathrm{m06}$ & $1995 \mathrm{m08}$ & $1995 \mathrm{m08}$ & $1995 \mathrm{m09}$ & $1995 \mathrm{m07}$ & $1995 \mathrm{mog}$ & $1995 \mathrm{m01}$ & $1995 \mathrm{m03}$ \\
\hline & $\mathrm{T}$ & $1996 \mathrm{~m} 12$ & $1996 \mathrm{~m} 12$ & $1996 \mathrm{mog}$ & $1996 \mathrm{~m} 10$ & $1996 \mathrm{~m} 10$ & $1997 \mathrm{m01}$ & $1997 \mathrm{mo5}$ & $1997 \mathrm{m01}$ & $1997 \mathrm{m01}$ \\
\hline \multirow{2}{*}{1 false signal } & $\mathrm{P}$ & & & & & & & & $1998 \mathrm{m09}$ & \\
\hline & $\mathrm{T}$ & & & & & & & & $1999 \mathrm{m04}$ & \\
\hline \multirow{2}{*}{ 3rd crisis } & $\mathrm{P}$ & $2001 \mathrm{m01}$ & $2001 \mathrm{m01}$ & $2001 \mathrm{~m} 02$ & $2001 \mathrm{~m} 01$ & $2001 \mathrm{m02}$ & $2001 \mathrm{~m} 01$ & $2001 \mathrm{m04}$ & $2001 \mathrm{m03}$ & $2000 \mathrm{~m} 12$ \\
\hline & $\mathrm{T}$ & $2003 \mathrm{~m} 07$ & $2003 \mathrm{~m} 06$ & $2003 \mathrm{~m} 04$ & $2002 \mathrm{~m} 11$ & $2003 \mathrm{m03}$ & $2002 \mathrm{m07}$ & $2003 \mathrm{~m} 12$ & $2003 \mathrm{~m} 09$ & $2003 \mathrm{~m} 06$ \\
\hline \multirow{2}{*}{2 false signal } & $\mathrm{P}$ & & & & & & & & $2005 \mathrm{m02}$ & \\
\hline & $\mathrm{T}$ & & & & & & & & $2005 \mathrm{m07}$ & \\
\hline \multirow{2}{*}{4 th crisis } & $\mathrm{P}$ & $2007 \mathrm{mo9}$ & $2007 \mathrm{mog}$ & $2008 \mathrm{m04}$ & $2008 \mathrm{~m} 04$ & $2008 \mathrm{m04}$ & $2008 \mathrm{m04}$ & $2008 \mathrm{m04}$ & $2008 \mathrm{m04}$ & $2007 \mathrm{~m} 12$ \\
\hline & $\mathrm{T}$ & $2009 \mathrm{~m} 09$ & $2009 \mathrm{~m} 11$ & $2009 \mathrm{m05}$ & $2009 \mathrm{~m} 06$ & $2009 \mathrm{~m} 09$ & $2009 \mathrm{m04}$ & $2009 \mathrm{~m} 09$ & $2009 \mathrm{m08}$ & $2009 \mathrm{mo6}$ \\
\hline \multirow{2}{*}{5 th crisis } & $\mathrm{P}$ & $2011 \mathrm{~m} 09$ & $2011 \mathrm{m09}$ & $2011 \mathrm{m09}$ & $2012 \mathrm{m07}$ & $2012 \mathrm{m05}$ & $2011 \mathrm{~m} 09$ & $2011 \mathrm{~m} 06$ & $2011 \mathrm{m03}$ & $2011 \mathrm{mog}$ \\
\hline & $\mathrm{T}$ & $2013 \mathrm{m07}$ & $2013 \mathrm{m08}$ & $2012 \mathrm{~m} 10$ & $2012 \mathrm{~m} 11$ & $2013 \mathrm{m07}$ & $2012 \mathrm{~m} 11$ & $2013 \mathrm{m07}$ & $2013 \mathrm{m08}$ & $2013 \mathrm{~m} 01$ \\
\hline
\end{tabular}

Let us note that although the two methods provide rather close results, we suggest using the two-step method as it is more robust and easier to estimate and allows to consider big datasets. Furthermore, since the factor is considered as observed, the baseline specification can be extended to include additional autoregressive lags and other explanatory variables. For example, we suggest the following possible extensions of the baseline model (section "Other specifications of MS-DFM" in Table 1): introduction of switching variance, use of two more lags in the autoregressive structure, inclusion of the second and the fourth principal in the dynamics equation of the factor to take 
into account the information left aside by the first principal component. Some of these extensions increase the performance of the baseline specifications, although the improvement is rather minor if not negligible. Nevertheless this observation leaves room for further research in the direction of multifactor markov-switching dynamic factor models with a general VAR structure.

As an additional validity check, we make two more comparisons. The first one serves to evaluate the gain from the multivariate analysis. For this purpose we made a comparison with the results of a simple classical Hamilton (1989) model with two autoregressive terms and a switching constant estimated on the growth rate of the index of industrial production (see Table 1). One can see that, contrary to the United States, in case of France this series contains much less information about the business cycles, at least for the period under consideration. The MS-AR model produces only one signal corresponding to the 2008 recession, this poor performance being reflected in our quantitative indicators as high QPS and FPS and very low correlation with the reference.

Secondly, to understand the role of the number of series for the two-step method, we analyze its performance on smaller datasets. A number of papers (see, for example, Boivin and $\mathrm{Ng}$ (2006) and Bai and Ng (2008)) state that using big datasets for factor analysis is not always better than using smaller datasets of appropriately selected series. To evaluate the role of the number of series for the two-step method we estimate the baseline specification on the varying dataset, i.e. on the subset of 25 series which were used for one-step method as well as on the 13 series which were finally retained ("Two-step method on 25 series" and "Two-step method on 13 series", respectively, in the Table 1). As we can see, the use of 13 series does not ameliorate the results of the benchmark Hamilton (1989) model. The most likely reason for this is that the PCA estimate of the factor is not good enough to give meaningful results. However, when the number of series increase to 25 , the results become much closer to the results on the full dataset ("Two-step method, full dataset"): QPS and FPS are almost identical $(Q P S=0.12, F P S / T=0.21$ for 25 series, $Q P S=0.14, F P S / T=0.19$ for the full dataset), the correlation with the OECD reference is much closer $(C o r r=0.57$ and Corr $=0.67$ for 25 series and the full dataset, respectively), although the beginnings and the ends of recessions are estimated with less precision. To conclude, this exercise shows that the larger the dataset is, the more accurate the estimates of the factor are, and therefore the better the quality of the extracted signal is, although the marginal gain of a larger number of series decreases.

\section{Conclusion}

This paper focuses on the comparison of the two estimation methods of the MS-DFM model of the business cycle applied to the French data. The Maximum Likelihood estimation of the model in one-step can be run only for a very small set of information, whereas the two-step estimation can accommodate much bigger information sets. In this paper we use an extensive dataset of French series covering the period March 1993 - October 2013. We estimate the MS-DFM on 151 series in two steps and on different subsets by 4 series of main economic indicators in one step. We show that the two-step estimation procedure does produce good results in terms of turning points identification. The applied procedures are absolutely transparent and replicable. The model produces turning point estimates up to two months earlier than the reference OECD dating, which is an important gain in timing for economic agents and policymakers. 
We find that both estimation methods provide qualitatively similar results: the common factor of several specific economic series (in case of one-step method) and the first principal component of a large set of series (in case of two-step method) can be characterized as having two distinct phases with low and high growth rates, correspondingly. The two-step method also allows to detect the difference in the magnitude of variance in the factor dynamics. For both methods, the periods of high filtered probability of recession match the OECD recessions. In the same time, the two-step method and several results of the one-step method identify short recessions in 1998 and 2005 that do not appear in the OECD dating as it is conceived to detect long-lasting phases. We show that these signals are not false, as the worsening of economic situation was marked in the corresponding short term INSEE reports, as well as captured by the Index of reversal by INSEE and the datings obtained with the help of Christiano-Fitzgerald filter.

Both methods largely outperform the results of the univariate Hamilton (1989) model estimated on the index of industrial production, which shows the importance of the multivariate framework for the business cycle turning point identification.

The results of one-step method differ greatly depending on the composition of the 4 input economic series. We identify the most explicative series (retail trade order intentions, number of job seekers, the survey on manufacturing business situation future and construction confidence index) and the series that produce extra signals (manufacturing finished goods stock level, price return on FTSE equity index and Manufacturing Industrial Confidence Indicator) and determine 7 sets of series which perform best in terms of concordance of estimated turning points with OECD chronology. Since the size of the dataset considered with one-step method is generally limited to 4 series, it seems reasonable to use several sets (i.e. several results of one-step estimation) as complements to overcome the information constraint.

Using a more comprehensive dataset with two-step method allows us to obtain more accurate estimates of the beginning and the end of recessions. We show that the number of series plays an important role, the larger dataset leading to more accurate identification of the turning points. Introduction of additional autoregressive lags and other principal components may further enhance the precision of the two-step results, although the improvement is minor.

We conclude that either method can be used to replicate the OECD dating. Nevertheless, we think the use of the two-step method is very appealing: it allows to get a valid dating of turning points without going through a complicated procedure of series selection, it is much less time-consuming and the numerical convergence problems are not frequent. Another advantage of the two-step method is that it opens the way to different extensions. First, the factor may be estimated within the first step using other methods like the 2-step estimator proposed by Doz et al. (2011) or the QML estimator proposed by Doz et al. (2012): this will allow to use data of different frequencies, with missing observations or ragged ends. Second, multifactor markov-switching models can be estimated. These extensions are left for future research. 


\section{References}

Anas, J., Billio, M. and Ferrara, L. Do Luca, M. (2007), 'A turning point chronology for the euro-zone', Working Papers, Department of Economics, University of Venice "Ca' Foscari" 33.

Anas, J., Billio, M., Ferrara, L. and Mazzi, G. L. (2008), 'A system for dating and detecting turning points in the euro area', The Manchester School 76, 549-577.

Bai, J. (2003), 'Inferential theory for factor models of large dimensions', Econometrica 71, 135-171.

Bai, J. and Ng, S. (2008), 'Forecasting economic time series using targeted predictors', Journal of Econometrics 146, 304-317.

Bardaji, J., Clavel, L. and Tallet, F. (2008), 'Deux nouveau indicateurs pour aider au diagnostic conjoncturel en france', Dossiers, INSEE .

Bardaji, J., Clavel, L. and Tallet, F. (2009), 'Constructing a markov-switching turning point index using mixed frequencies with an alpplication to french business survey data', OECD Jounal: Journal of Business Cycle Measurement and Analysis 2.

Bessec, M. and Bouabdallah, O. (2014), 'Forecasting gdp over the business cycle in a multi-frequency and data-rich environment', Oxford Bulletin of Economics and Statistics pp. n/a-n/a.

URL: $h t t p: / / d x$.doi.org/10.1111/obes.12069

Bessec, M. and Doz, C. (2012), 'Prévision à court terme de la croissance du pib français à l'aide de modèles à facteurs dynamiques', Economie 63 prévision .

Boivin, J. and Ng, S. (2006), 'Are more data always better for factor analysis?', Journal of Econometrics 132, 169-194.

Bruno, G. and Otranto, E. (2004), 'Dating the italian business cycle: A comparison of procedures', ISAE Working Papers, ISTAT - Italian National Institute of Statistics - (Rome, ITALY). 41.

Burns, A. F. and Mitchell, W. C. (1964), Measuring Business Cycles, National Bureau of Economic Research - Business \& Economics.

Camacho, M., Perez-Quiros, G. and Poncela, P. (2012), 'Extracting nonlinear signals from several economic indicators', Banco de Espaïna Working Papers 1202, Banco de Espana. pp. 1-36.

Carvalho, C. M. and Lopes, H. F. (2007), 'Factor stochastic volatility with time varying loadings and markov and switching regimes', Journal of Statistical Planning and Inference 6, 3082-3091.

Chauvet, M. (1998), 'An Econometric Characterization of Business Cycle Dynamics with Factor Structure and Regime Switching', International Economic Review, Department of Economics, University of Pennsylvania and Osaka University Institute of Social and Economic Research Association 39(4), 969-96.

Chauvet, M. (1999), 'Stock market Fluctuations and the business cycle', Journal of Economic and Social Measurement 25(3,4), 1-31.

Chauvet, M. and Potter, S. (1998), 'Nonlinear risk', Macroeconomic Dynamics, Cambridge University Press 5(04), 621-646. 
Chauvet, M. and Senyuz, Z. (2008), A Joint Dynamic Bi-Factor Model of the Yield Curve and the Economy as a Predictor of Business Cycles, MPRA Paper 15076, University Library of Munich, Germany.

URL: $h t t p: / /$ ideas.repec.org $/ \mathrm{p} / \mathrm{pra} / \mathrm{mprapa} / 15076 . h t m l$

Chauvet, M. and Yu, C. (2006), 'International Business Cycles : G7 and OECD countries', Economic Review, Federal Reserve Bank of Atlanta (Q1), 43-54.

Chen, X. (2007), Evaluating the Synchronisation of the Eurozone Business Cycles Using Multivariate Coincident Macroeconomic Indicators.

Darné, O. and Ferrara, L. (2011), 'Identification of Slowdowns and Accelerations for the Euro Area Economy', Oxford Bulletin of Economics and Statistics, Department of Economics, University of Oxford 73(3), 335-364.

Diebold, F. X. and Rudebusch, G. D. (1996), 'Measuring Business Cycles: A Modern Perspective', The Review of Economics and Statistics 78(1), 67-77.

Dolega, M. (2007), Tracking Canadian Trend Productivity : A Dynamic Factor Model with Markov Switching.

Doz, C., Giannone, D. and Reichlin, L. (2011), 'A two-step estimator for large approximate dynamic factor models based on kalman filtering', Journal of Econometrics 164(1), 188-205.

Doz, C., Giannone, D. and Reichlin, L. (2012), 'A Quasi-Maximum Likelihood Approach for Large, Approximate Dynamic Factor Models', The Review of Economics and Statistics 94(4), 10141024.

URL: http://ideas.repec.org/a/tpr/restat/v94y2012i4p1014-1024.html

Dueker, M. and Sola, M. (2008), Multivariate Markov Switching With Weighted Regime Determination : giving France more weight than Finland.

Gregoir, S. and Lenglart, F. (2000), 'Measuring the Probability of a Business Cycle Turning Point by Using a Multivariate Qualitative Hidden Markov Model', Journal of Forecasting 102(May 1998), 81-102.

Hamilton, J. D. (1989), 'A new approach to the economic analysis of nonstationary time series and the business cycle', Econometrica 57, 357-384.

Kaufmann, S. (2000), 'Measuring business cycles with a dynamic markov switching factor model: an assessment using bayesian simulation methods', Econometrics Journal 3, 39-65.

Kholodilin, K. A. (2002a), 'Some Evidence of Decreasing Volatility of the US Coincident Economic Indicator', Economics Bulletin, AccessEcon 3(20), 1-20.

Kholodilin, K. A. (2002b), 'Two Alternative Approaches to Modelling the Nonlinear Dynamics of the Composite Economic Indicator', Economics Bulletin, AccessEcon 3(26), 1-18.

Kholodilin, K. A. (2006), 'Using the dynamic bi-factor model with markov switching to predict the cyclical turns in the large european economies', DIW Berlin, discussion paper . 
Kholodilin, K. A. and Yao, W. V. (2004), Business Cycle Turning Points : Mixed-Frequency Data with Structural Breaks.

Kim, C.-J. (1994), 'Dynamic linear models with Markov-switching', Journal of Econometrics 60(12), $1-22$.

URL: http://ideas.repec.org/a/eee/econom/v60y1994i1-2p1-22.html

Kim, C.-j. and Nelson, C. R. (1998), 'Business Cycle Turning Points, a New Coincident Index, and Tests of Duration Dependence qsed on the Dynamic Factor Model with Regime Switching', The Review of Economics and Statistics 80(2), 188-201.

Kim, M.-J. and Yoo, J.-S. (1995), 'New index of coincident indicators: A multivariate Markov switching factor model approach', Journal of Monetary Economics 36(3), 607-630.

Stock, J. H. and Watson, M. W. (1989), 'New indexes of coincident and leading economic indicators', Macroeconomics Annual 4.

Stock, J. H. and Watson, M. W. (2002), 'Forecasting using principal components from a large number of predictors', Journal of the American Statistical Association Vol. 9, No. 460, 11671179 .

Stock, J. H. and Watson, M. W. (2010), 'Estimating turning points using large data sets', NBER Working Papers 16532. 


\section{Appendix A. Datasets}

Table A.1. Series used for the two-step estimation

\begin{tabular}{|c|c|c|c|}
\hline Series full name & Source & SA & Lag \\
\hline \multicolumn{4}{|l|}{ Industrial production by industry } \\
\hline \multicolumn{4}{|l|}{ General } \\
\hline France, OECD MEI, Production Of Total Industry, SA, Change $\mathrm{P} / \mathrm{P}$ & Macrobond & SA & 2 \\
\hline France, OECD MEI, Production Of Total Industry, SA, Index & Macrobond & SA & 2 \\
\hline France, OECD MEI, Production Of Total Manufactured Intermediate Goods, SA, Index & Macrobond & SA & 2 \\
\hline France, OECD MEI, Production In Total Manufacturing, SA, Index & Macrobond & SA & 2 \\
\hline France, OECD MEI, Production Of Total Manufactured Investment Goods, SA, Index & Macrobond & SA & 2 \\
\hline France, Industrial Production, Total Industry Excluding Construction, Calendar Adjusted, SA, Index & Macrobond & SA & 1 \\
\hline France, Capacity Utilization, Total Industry, SA & Macrobond & SA & 0 \\
\hline \multicolumn{4}{|l|}{ Mining } \\
\hline $\begin{array}{l}\text { France, Eurostat, Industry Production Index, Extraction of Crude Petroleum \& Natural Gas, Calendar Adjusted, Change } \\
\mathrm{Y} / \mathrm{Y}\end{array}$ & Macrobond & & 1 \\
\hline France, Eurostat, Industry Production Index, Other Mining \& Quarrying, Calendar Adjusted, Change Y/Y & Macrobond & & 1 \\
\hline France, Eurostat, Industry Production Index, Mining \& Quarrying, Calendar Adjusted, Change Y/Y & Macrobond & & 1 \\
\hline \multicolumn{4}{|l|}{ Nondurables } \\
\hline France, Eurostat, Industry Production Index, Manufacture of Food Products, Calendar Adjusted, Change Y/Y & Macrobond & & 1 \\
\hline France, Eurostat, Industry Production Index, Manufacture of Beverages, Calendar Adjusted, Change Y/Y & Macrobond & & 1 \\
\hline France, Eurostat, Industry Production Index, Manufacture of Tobacco Products, Calendar Adjusted, Change Y/Y & Macrobond & & 1 \\
\hline France, Eurostat, Industry Production Index, Manufacture of Textiles, Calendar Adjusted, Change Y/Y & Macrobond & & 1 \\
\hline France, Eurostat, Industry Production Index, Manufacture of Wearing Apparel, Calendar Adjusted, Change Y/Y & Macrobond & & 1 \\
\hline $\begin{array}{l}\text { France, Eurostat, Industry Production Index, Manufacture of Leather \& Related Products, Calendar Adjusted, Change } \\
\mathrm{Y} / \mathrm{Y}\end{array}$ & Macrobond & & 1 \\
\hline France, Eurostat, Industry Production Index, Manufacture of Paper \& Paper Products, Calendar Adjusted, Change Y/Y & Macrobond & & 1 \\
\hline $\begin{array}{l}\text { France, Eurostat, Industry Production Index, Printing \& Service Activities Related to Printing, Calendar Adjusted, } \\
\text { Change } \mathrm{Y} / \mathrm{Y}\end{array}$ & Macrobond & & 1 \\
\hline $\begin{array}{l}\text { France, Eurostat, Industry Production Index, Manufacture of Coke \& Refined Petroleum Products, Calendar Adjusted, } \\
\text { Change Y/Y }\end{array}$ & Macrobond & & 1 \\
\hline $\begin{array}{l}\text { France, Eurostat, Industry Production Index, Manufacture of Chemicals \& Chemical Products, Calendar Adjusted, Change } \\
\mathrm{Y} / \mathrm{Y}\end{array}$ & Macrobond & & 1 \\
\hline France, Eurostat, Industry Production Index, Manufacture of Rubber Products, Calendar Adjusted, Change Y/Y & Macrobond & & 1 \\
\hline \multicolumn{4}{|l|}{ Durables } \\
\hline $\begin{array}{l}\text { France, Eurostat, Industry Production Index, Manufacture of Computer, Electronic \& Optical Products, Calendar } \\
\text { Adjusted, Change } \mathrm{Y} / \mathrm{Y}\end{array}$ & Macrobond & & 1 \\
\hline $\begin{array}{l}\text { France, Eurostat, Industry Production Index, Manufacture of Electric Motors, Generators, Transformers \& Electricity } \\
\text { Distribution \& Control Apparatus, Calendar Adjusted, Change Y/Y }\end{array}$ & Macrobond & & 1 \\
\hline France, Eurostat, Industry Production Index, Manufacture of Electrical Equipment, Calendar Adjusted, Change Y/Y & Macrobond & & 1 \\
\hline $\begin{array}{l}\text { France, Eurostat, Industry Production Index, Manufacture of Machinery \& Equipment N.E.C., Calendar Adjusted, Change } \\
\mathrm{Y} / \mathrm{Y}\end{array}$ & Macrobond & & 1 \\
\hline $\begin{array}{l}\text { France, Eurostat, Industry Production Index, Manufacture of Motor Vehicles, Trailers, Semi-Trailers \& of Other Transport } \\
\text { Equipment, Calendar Adjusted, Change } \mathrm{Y} / \mathrm{Y}\end{array}$ & Macrobond & & 1 \\
\hline France, Eurostat, Industry Production Index, Building of Ships \& Boats, Calendar Adjusted, Change Y/Y & Macrobond & & 1 \\
\hline
\end{tabular}


France, Eurostat, Industry Production Index, Manufacture of Furniture, Calendar Adjusted, Change Y/Y

France, Eurostat, Industry Production Index, Manufacturing, Calendar Adjusted, Change Y/Y

France, Eurostat, Construction, Building \& Civil Engineering, Construction \& Production Index, Buildings, Calendar

Adjusted, Change $\mathrm{Y} / \mathrm{Y}$

France, Eurostat, Construction, Building \& Civil Engineering, Construction \& Production Index, Civil Engineering Works,

Calendar Adjusted, Change $\mathrm{Y} / \mathrm{Y}$

France, Eurostat, Construction, Building \& Civil Engineering, Construction \& Production Index, Construction, Calendar

Adjusted, Change $\mathrm{Y} / \mathrm{Y}$

France, Metropolitan, Construction by Status, Number, Permits, Residential Buildings, Total

France, Metropolitan, Construction by Status, Number, Housing Starts, Residential Buildings, Total

France, Construction by Status, Number, Permits, Residential Buildings, Total

France, Construction by Status, Number, Housing Starts, Residential Buildings, Total

Utilities

France, Eurostat, Industry Production Index, Electricity, Gas, Steam \& Air Conditioning Supply, Total, Calendar

Adjusted, Change $\mathrm{Y} / \mathrm{Y}$

Industrial production by market

Durables

France, Eurostat, Industry Production Index, MIG - Capital Goods, Calendar Adjusted, Change Y/Y

France, Eurostat, Industry Production Index, MIG - Consumer Goods (Except Food, Beverages \& Tobacco), Calendar

Adjusted, Change $\mathrm{Y} / \mathrm{Y}$

France, Eurostat, Industry Production Index, MIG - Durable Consumer Goods, Calendar Adjusted, Change Y/Y

France, Eurostat, Industry Production Index, MIG - Intermediate \& Capital Goods, Calendar Adjusted, Change Y/Y

France, Eurostat, Industry Production Index, MIG - Intermediate Goods, Calendar Adjusted, Change Y/Y

France, Eurostat, Industry Production Index, MIG - Consumer Goods, Calendar Adjusted, Change Y/Y

France, Expenditure Approach, Household Consumption Expenditure, Automobiles, Calendar Adjusted, Constant Prices,

SA, EUR

France, Expenditure Approach, Household Consumption Expenditure, Housing Equipment, Calendar Adjusted, Constant

Prices, SA, EUR

France, Expenditure Approach, Household Consumption Expenditure, Durable Personal Equipment, Calendar Adjusted,

Constant Prices, SA, EUR

Nondurables

France, Eurostat, Industry Production Index, MIG - Non-Durable Consumer Goods, Calendar Adjusted, Change Y/Y

France, Eurostat, Industry Production Index, MIG - Energy (Except D \& E), Calendar Adjusted, Change Y/Y

France, Eurostat, Industry Production Index, MIG - Energy (Except Section E), Calendar Adjusted, Change Y/Y

France, Energy Production, Transmission \& Distribution, Electric Power Generation, Transmission \& Distribution,

Calendar Adjusted, SA, Index

France, Eurostat, Industry Production Index, Manufacture of Products of Wood, Cork, Straw \& Plaiting Materials,

Calendar Adjusted, Index

France, Eurostat, Industry Production Index, Manufacture of Basic Metals \& Fabricated Metal Products, Except

Machinery \& Equipment, Index

France, Expenditure Approach, Household Consumption Expenditure, Textiles \& Leather, Calendar Adjusted, Constant

Prices, SA, EUR

France, Expenditure Approach, Household Consumption Expenditure, Other Manufactured Goods, Calendar Adjusted,

Constant Prices, SA, EUR

France, Expenditure Approach, Household Consumption Expenditure, Energy, Water \& Waste Treatment, Calendar

Adjusted, Constant Prices, SA, EUR

\begin{tabular}{l|} 
Macrobond \\
Macrobond \\
Macrobond \\
Macrobond \\
Macrobond \\
Macrobond \\
Macrobond \\
Macrobond \\
Macrobond
\end{tabular}

Macrobon

\begin{tabular}{l|l|l} 
& & \\
\end{tabular}


France, Expenditure Approach, Household Consumption Expenditure, Petroleum Products, Calendar Adjusted, Constant Prices, SA, EUR

France, Expenditure Approach, Household Consumption Expenditure, Food, Calendar Adjusted, Constant Prices, SA, EUR France, Expenditure Approach, Household Consumption Expenditure, Goods, Calendar Adjusted, Constant Prices, SA, EUR
France, Manufacturing, Computers \& Peripheral Equipment, Calendar Adjusted, SA, Index

France, Manufacturing, Optical Instruments \& Photographic Equipment, Calendar Adjusted, SA, Index

France, Manufacturing, Electric Lighting Equipment, Calendar Adjusted, SA, Index

France, Manufacturing, Other Electrical Equipment, Calendar Adjusted, SA, Index

France, Manufacturing, Repair of Fabricated Metal Products, Machinery \& Equipment, Calendar Adjusted, SA, Index

France, Manufacturing, Electrical Equipment, Calendar Adjusted, SA, Index

Materials

France, Manufacturing, Clay Building Materials, Calendar Adjusted, SA, Index

\section{Employment by skill and gender}

France, Metropolitan, Unemployment, Job Seekers, Men, Total, Categories A, B \& C, Calendar Adjusted, SA

France, Metropolitan, Unemployment, Job Seekers, Women \& Men, Under 25 Years, Categories A, B \& C, Calendar

Adjusted, SA

France, Metropolitan, Unemployment, Job Seekers, Women \& Men, Aged 25-49 Years, Categories A, B \& C, Calendar Adjusted, SA

France, Metropolitan, Unemployment, Job Seekers, Women \& Men, Aged 50 \& More, Categories A, B \& C, Calendar Adjusted, SA

France, Unemployment, Job Seekers, Women \& Men, Total, Categories A, B \& C, Calendar Adjusted, SA

France, Metropolitan, Unemployment, Job Seekers, Men, Under 25 Years, Categories A, B \& C

France, Metropolitan, Unemployment, Job Seekers, Men, Aged 25-49 Years, Categories A, B \& C

France, Metropolitan, Unemployment, Job Seekers, Men, Aged 50 \& More, Categories A, B \& C

France, Metropolitan, Unemployment, Job Seekers, Men, Total, Categories A, B \& C

France, Metropolitan, Unemployment, Job Seekers, Women, Under 25 Years, Categories A, B \& C

France, Metropolitan, Unemployment, Job Seekers, Women, Aged 25-49 Years, Categories A, B \& C

France, Metropolitan, Unemployment, Job Seekers, Women, Aged 50 \& More, Categories A, B \& C

France, Metropolitan, Unemployment, Job Seekers, Women, Total, Categories A, B \& C

France, Metropolitan, Unemployment, Job Seekers, Women \& Men, Under 25 Years, Categories A, B \& C

France, Metropolitan, Unemployment, Job Seekers, Women \& Men, Aged 25-49 Years, Categories A, B \& C

France, Metropolitan, Unemployment, Job Seekers, Women \& Men, Aged 50 \& More, Categories A, B \& C

France, Metropolitan, Unemployment, Job Seekers, Women \& Men, Total, Categories A, B \& C

France, Unemployment, Job Seekers, Women \& Men, Total, Categories A, B \& C

France, Metropolitan, Unemployment, Job Seekers, Men, Labourers, Categories A, B \& C

France, Metropolitan, Unemployment, Job Seekers, Women, Labourers, Categories A, B \& C

France, Metropolitan, Unemployment, Job Seekers, Women \& Men, Labourers, Categories A, B \& C

France, Metropolitan, Unemployment, Job Seekers, Men, Professional Workers, Categories A, B \& C

France, Metropolitan, Unemployment, Job Seekers, Women, Professional Workers, Categories A, B \& C

France, Metropolitan, Unemployment, Job Seekers, Women \& Men, Professional Workers, Categories A, B \& C

France, Metropolitan, Unemployment, Job Seekers, Men, Skilled Manual Workers, Categories A, B \& C

France, Metropolitan, Unemployment, Job Seekers, Women, Skilled Manual Workers, Categories A, B \& C

France, Metropolitan, Unemployment, Job Seekers, Women \& Men, Skilled Manual Workers, Categories A, B \& C

France, Metropolitan, Unemployment, Job Seekers, Men, Non-Qualified Employed Persons, Categories A, B \& C

\begin{tabular}{|l|c|c} 
Macrobond & SA & 1 \\
Macrobond & SA & 1 \\
Macrobond & SA & 1
\end{tabular}

\begin{tabular}{l|c|c} 
Macrobond & SA & 1 \\
Macrobond & SA & 1 \\
Macrobond & SA & 1 \\
Macrobond & SA & 1 \\
Macrobond & SA & 1 \\
\end{tabular}

Macrobond

\begin{tabular}{|l|l|l|}
\hline Macrobond & SA & 1 \\
\hline
\end{tabular}

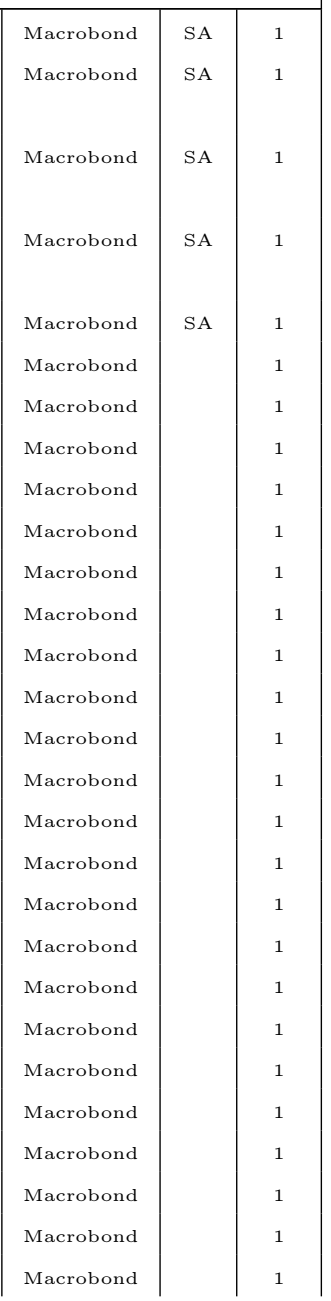




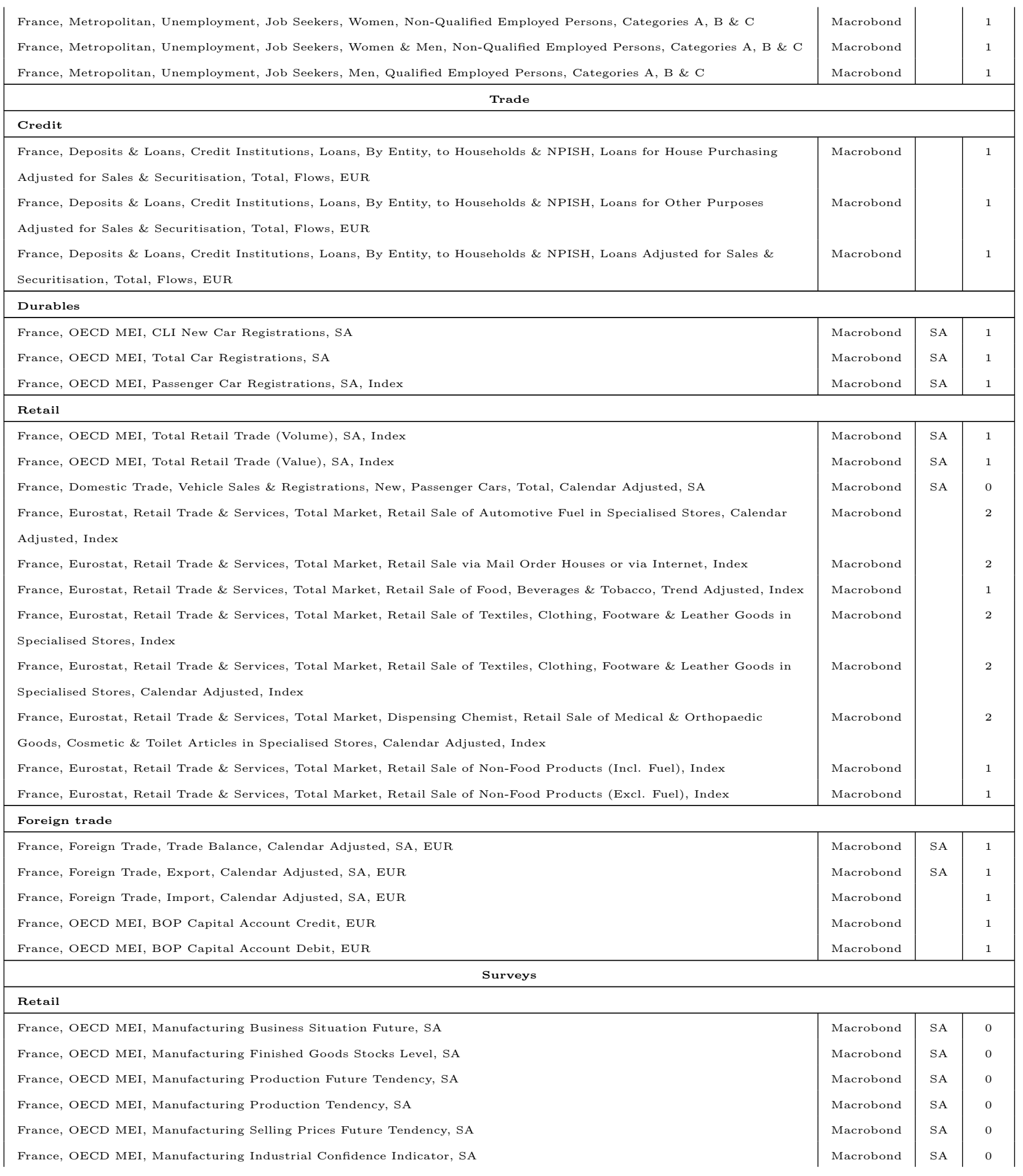




\begin{tabular}{|c|c|c|c|}
\hline France, OECD MEI, Manufacturing Export Order Books Level, SA & Macrobond & SA & 0 \\
\hline \multicolumn{4}{|l|}{ Consumers } \\
\hline $\begin{array}{l}\text { France, Consumer Surveys, INSEE, Consumer Confidence Indicator, General Economic Situation, Past } 12 \text { Months, Balance } \\
\text { of Replies, SA }\end{array}$ & Macrobond & SA & 0 \\
\hline $\begin{array}{l}\text { France, Consumer Surveys, INSEE, Consumer Confidence Indicator, General Economic Situation, Next } 12 \text { Months, Balance } \\
\text { of Replies, SA }\end{array}$ & Macrobond & $\mathrm{SA}$ & 0 \\
\hline $\begin{array}{l}\text { France, Consumer Surveys, INSEE, Consumer Confidence Indicator, Major Purchases Intentions, Next } 12 \text { Months, Balance } \\
\text { of Replies, SA }\end{array}$ & Macrobond & $\mathrm{SA}$ & 0 \\
\hline $\begin{array}{l}\text { France, Consumer Surveys, INSEE, Consumer Confidence Indicator, Financial Situation, Last } 12 \text { Months, Balance of } \\
\text { Replies, SA }\end{array}$ & Macrobond & $\mathrm{SA}$ & 0 \\
\hline $\begin{array}{l}\text { France, Consumer Surveys, INSEE, Consumer Confidence Indicator, Financial Situation, Next } 12 \text { Months, Balance of } \\
\text { Replies, SA }\end{array}$ & Macrobond & SA & 0 \\
\hline \multicolumn{4}{|l|}{ Industry } \\
\hline France, Business Surveys, INSEE, Building Industry, Global, Past Activity Tendency & Macrobond & & 0 \\
\hline France, Business Surveys, INSEE, Building Industry, Global, Expected Activity & Macrobond & & 0 \\
\hline France, Business Surveys, INSEE, Building Industry, Global, Order Books Level & Macrobond & & 0 \\
\hline France, Business Surveys, INSEE, Building Industry, Global, Past Workforce Size & Macrobond & & 0 \\
\hline France, Business Surveys, Bank of France, Industry, Inventories of Final Goods, Manufacturing Industry, SA & Macrobond & $\mathrm{SA}$ & 0 \\
\hline France, Business Surveys, Bank of France, Industry, Current Order Books, Manufacturing Industry, SA & Macrobond & $\mathrm{SA}$ & 0 \\
\hline France, Business Surveys, INSEE, Industry, Manufacturing, Personal Production Expectations, Balance of Replies, SA & Macrobond & $\mathrm{SA}$ & 0 \\
\hline France, Business Surveys, INSEE, Industry, Manufacturing, Demand \& Export Order Books, Balance of Replies, SA & Macrobond & SA & 0 \\
\hline France, Business Surveys, INSEE, Industry, Manufacturing, General Production Expectations, Balance of Replies, SA & Macrobond & $\mathrm{SA}$ & 0 \\
\hline France, Business Surveys, DG ECFIN, Retail Trade Confidence Indicator, Balance, SA & Macrobond & $\mathrm{SA}$ & 0 \\
\hline France, Business Surveys, DG ECFIN, Construction Confidence Indicator, Balance, SA & Macrobond & $\mathrm{SA}$ & 0 \\
\hline $\begin{array}{l}\text { France, Business Surveys, Bank of France, Industry, Current Order Books, Manufacture of Food Products, Beverages \& } \\
\text { Tobacco Products, SA }\end{array}$ & Macrobond & $\mathrm{SA}$ & 0 \\
\hline $\begin{array}{l}\text { France, Business Surveys, Bank of France, Industry, Current Order Books, Manufacture of Electrical, Computer \& } \\
\text { Electronic Equipment, Manufacture of Machinery, SA }\end{array}$ & Macrobond & $\mathrm{SA}$ & 0 \\
\hline France, Business Surveys, Bank of France, Industry, Current Order Books, Computer, Electronic \& Optical Products, SA & Macrobond & $\mathrm{SA}$ & 0 \\
\hline France, Business Surveys, Bank of France, Industry, Current Order Books, Machinery \& Equipment, SA & Macrobond & SA & 0 \\
\hline France, Business Surveys, Bank of France, Industry, Current Order Books, Transport Equipment, SA & Macrobond & SA & 0 \\
\hline France, Business Surveys, Bank of France, Industry, Current Order Books, Automotive Industry, SA & Macrobond & $\mathrm{SA}$ & 0 \\
\hline France, Business Surveys, Bank of France, Industry, Current Order Books, Other Transport Equipment, SA & Macrobond & SA & 0 \\
\hline France, Business Surveys, Bank of France, Industry, Current Order Books, Other Manufacturing, SA & Macrobond & SA & 0 \\
\hline France, Business Surveys, Bank of France, Industry, Current Order Books, Metal \& Metal Products Manufacturing, SA & Macrobond & $\mathrm{SA}$ & 0 \\
\hline $\begin{array}{l}\text { France, Business Surveys, Bank of France, Industry, Current Order Books, Other Manufacturing Industries (Including } \\
\text { Repair \& Installation of Machinery), SA }\end{array}$ & Macrobond & $\mathrm{SA}$ & 0 \\
\hline \multicolumn{4}{|l|}{ Services } \\
\hline France, Service Surveys, DG ECFIN, Services Confidence Indicator, Balance, SA & Macrobond & SA & 0 \\
\hline $\begin{array}{l}\text { France, Service Surveys, INSEE, Services, Past Trend of Employment, All Non-Temporary Services, Including } \\
\text { Transportation, Balance of Replies, SA }\end{array}$ & Macrobond & $\mathrm{SA}$ & 0 \\
\hline $\begin{array}{l}\text { France, Service Surveys, INSEE, Services, Expected Trend of Activity, All Non-Temporary Services, Including } \\
\text { Transportation, Balance of Replies, SA }\end{array}$ & Macrobond & SA & 0 \\
\hline $\begin{array}{l}\text { France, Service Surveys, INSEE, Services, Past Trend of Activity, All Non-Temporary Services, Including Transportation, } \\
\text { Balance of Replies, SA }\end{array}$ & Macrobond & $\mathrm{SA}$ & 0 \\
\hline
\end{tabular}




\begin{tabular}{|c|c|c|c|}
\hline \multicolumn{4}{|l|}{ Retail trade } \\
\hline $\begin{array}{l}\text { France, Business Surveys, DG ECFIN, Retail Trade Confidence Indicator, Business Activity (Sales) Development over the } \\
\text { Past } 3 \text { Months, Balance, SA }\end{array}$ & Macrobond & SA & 0 \\
\hline $\begin{array}{l}\text { France, Business Surveys, DG ECFIN, Retail Trade Confidence Indicator, Business Activity Expectations over the Next } 3 \\
\text { Months, Balance, SA }\end{array}$ & Macrobond & SA & 0 \\
\hline $\begin{array}{l}\text { France, Business Surveys, DG ECFIN, Retail Trade Confidence Indicator, Employment Expectations over the Next } 3 \\
\text { Months, Balance, SA }\end{array}$ & Macrobond & SA & 0 \\
\hline France, OECD MEI, Retail Trade Orders Intentions, SA & Macrobond & SA & 0 \\
\hline \multicolumn{4}{|l|}{ Prices } \\
\hline France, Consumer Price Index, Total, Index & Macrobond & & 0 \\
\hline France, Consumer Price Index, Housing, Water, Electricity, Gas \& Other Fuels, Rent of Primary Residence, Index & Macrobond & & 0 \\
\hline France, Eurostat, Producer Prices Index, Domestic Market, Manufacture of Plastics Products, Change P/P & Macrobond & & 1 \\
\hline Germany, Bundesbank, Price of Gold in London, Afternoon Fixing *, 1 Ounce of Fine Gold $=$ USD $\ldots$, USD & Macrobond & & 0 \\
\hline World, IMF IFS, International Transactions, Export Prices, Linseed Oil (Any Origin) & Macrobond & & 6 \\
\hline Commodity Indices, UNCTAD, Price Index, End of Period, USD & Macrobond & & 0 \\
\hline \multicolumn{4}{|l|}{ Financial sector } \\
\hline \multicolumn{4}{|l|}{ Indexes } \\
\hline NYSE Euronext Paris, cac40 ( $\curvearrowright$ FCHI), price index, beginning of period, EUR & Macrobond & & 0 \\
\hline United Kingdom, Equity Indices, FTSE, All-Share, Index, Price Return, End of Period, GBP & Macrobond & & 0 \\
\hline $\begin{array}{l}\text { Germany, Bundesbank, Capital Market Statistics, General Survey, Key Figures from the Capital Market Statistics } 2 \text {, DAX } \\
\text { Performance Index, End } 1987=1000 \text {, End of Month, Index }\end{array}$ & Macrobond & & 0 \\
\hline Japan, Economic Sentiment Surveys, ZEW, Financial Market Report, Stock Market, Nikkei 225, Balance & Macrobond & & 0 \\
\hline United States, Equity Indices, S\&P, 500, Index (Shiller), Cyclically Adjusted P/E Ratio (CAPE) & Macrobond & & 0 \\
\hline \multicolumn{4}{|l|}{ Exchange rates } \\
\hline France, FX Indices, BIS, Real Effective Exchange Rate Index, CPI Based, Broad & Macrobond & & \\
\hline France, FX Indices, BIS, Nominal Effective Exchange Rate Index, Broad & Macrobond & & 0 \\
\hline REER Euro/Chinese yuan, CPI deflated & $\mathrm{BCE}$ & & 0 \\
\hline REER Euro/UK pound, CPI deflated & $\mathrm{BCE}$ & & 0 \\
\hline REER Euro/Japanese yen, CPI deflated & $\mathrm{BCE}$ & & 0 \\
\hline REER Euro/US dollar, CPI deflated & $\mathrm{BCE}$ & & 0 \\
\hline \multicolumn{4}{|l|}{ Interest rates } \\
\hline Taux de référence des bons de trésor à 3 mois - monthly average & BDF & & 0 \\
\hline Taux de référence des bons de trésor à 12 mois - monthly average & $\mathrm{BDF}$ & & 0 \\
\hline France, Government Benchmarks, Eurostat, Government Bond, 10 Year, Yield & Macrobond & & 0 \\
\hline \multicolumn{4}{|l|}{ Loans } \\
\hline $\begin{array}{l}\text { France, Deposits \& Loans, Credit Institutions, Loans, By Entity, to Domestic Non-Financial Corporations, Loans Adjusted } \\
\text { for Sales \& Securitisation, Total, EUR }\end{array}$ & Macrobond & & 1 \\
\hline $\begin{array}{l}\text { France, Deposits \& Loans, Credit Institutions, Loans, By Entity, to Domestic Non-Financial Corporations, Investment } \\
\text { Loans Adjusted for Sales \& Securitisation, Total, EUR }\end{array}$ & Macrobond & & 1 \\
\hline $\begin{array}{l}\text { France, Deposits \& Loans, Credit Institutions, Loans, By Entity, to Domestic Non-Financial Corporations, Short-Term } \\
\text { Loans Adjusted for Sales \& Securitisation, Total, EUR }\end{array}$ & Macrobond & & 1 \\
\hline $\begin{array}{l}\text { France, Deposits \& Loans, Credit Institutions, Loans, By Entity, to Domestic Non-Financial Corporations, Other Loans } \\
\text { Adjusted for Sales \& Securitisation, Total, EUR }\end{array}$ & Macrobond & & 1 \\
\hline \multicolumn{4}{|l|}{$\begin{array}{ll} & \text { Monetary aggregates }\end{array}$} \\
\hline France, Monetary Aggregates, M1, Total, EUR & Macrobond & & 1 \\
\hline
\end{tabular}




\begin{tabular}{|c|c|c|c|}
\hline $\begin{array}{l}\text { France, Monetary Aggregates, M2, Total, EUR } \\
\text { France, Monetary Aggregates, M3, Total, EUR }\end{array}$ & $\begin{array}{l}\text { Macrobond } \\
\text { Macrobond }\end{array}$ & & 2 \\
\hline \multicolumn{4}{|l|}{ International } \\
\hline Germany, Economic Sentiment Surveys, ZEW, Financial Market Report, Current Economic Situation, Balance & Macrobond & & 0 \\
\hline Germany, OECD MEI, Manufacturing Business Situation Present, SA & Macrobond & SA & 1 \\
\hline Germany, OECD MEI, Production Of Total Industry, SA, Index & Macrobond & SA & 3 \\
\hline United States, Employment, CPS, 16 Years \& Over, SA & Macrobond & SA & 1 \\
\hline United States, Unemployment, CPS, 16 Years \& Over, Rate, SA & Macrobond & SA & 1 \\
\hline United States, Industrial Production, Total, SA, Index & Macrobond & $\mathrm{SA}$ & 1 \\
\hline United States, Domestic Trade, Retail Trade, Retail Sales, Total, Calendar Adjusted, SA, USD & Macrobond & SA & 1 \\
\hline United States, Industrial Production, Industry Group, Manufacturing, Total (SIC), SA, Index & Macrobond & SA & 1 \\
\hline United States, Equity Indices, S\&P, 500, Index, Price Return, End of Period, USD & Macrobond & & 1 \\
\hline
\end{tabular}


Table A.2. List of series used for the one-step estimation

\begin{tabular}{|c|c|c|}
\hline $\mathrm{N}$ & Series name & Publication Lag \\
\hline 1 & France, Capacity Utilization, Total Industry, SA & 1 \\
\hline 2 & France, Consumer Surveys, INSEE, Consumer Confidence Indicator, Synthetic Index, SA & 0 \\
\hline 3 & $\begin{array}{l}\text { France, Domestic Trade, Vehicle Sales \& Registrations, New, Passenger Cars, Total, Calendar Adjusted, } \\
\text { SA }\end{array}$ & 0 \\
\hline 4 & France, OECD MEI, Retail Trade Orders Intentions, SA & 0 \\
\hline 5 & France, OECD MEI, CPI All Items, Change Y/Y & 3 \\
\hline 6 & France, OECD MEI, Production Of Total Industry, SA, Index & 3 \\
\hline 7 & France, OECD MEI, Total Retail Trade (Volume), SA, Change P/P & 1 \\
\hline 8 & $\begin{array}{l}\text { France, Metropolitan, Unemployment, Job Seekers, Men, Total, Categories A, B \& C, Calendar } \\
\text { Adjusted, SA }\end{array}$ & 1 \\
\hline 9 & France, OECD MEI, Manufacturing Finished Goods Stocks Level, SA & 0 \\
\hline 10 & France, Economic Sentiment Surveys, ZEW, Financial Market Report, Stock Market, CAC-40, Balance & 1 \\
\hline 11 & France, Foreign Trade, Trade Balance, Calendar Adjusted, SA, EUR & 1 \\
\hline 12 & France, Foreign Trade, Export, Calendar Adjusted, SA, EUR & 2 \\
\hline 13 & France, Foreign Trade, Import, Calendar Adjusted, SA, EUR & 2 \\
\hline 14 & Taux de référence des bons de trésor à 3 mois - monthly average & 3 \\
\hline 15 & Taux de référence des bons de trésor à 12 mois - monthly average & 3 \\
\hline 16 & United Kingdom, Equity Indices, FTSE, All-Share, Index, Price Return, End of Period, GBP & 0 \\
\hline 17 & Japan, Economic Sentiment Surveys, ZEW, Financial Market Report, Stock Market, Nikkei 225, Balance & 0 \\
\hline 18 & United States, Equity Indices, S\&P, 500, Index (Shiller), Cyclically Adjusted P/E Ratio (CAPE) & 0 \\
\hline 19 & France, OECD MEI, Manufacturing Business Situation Future, SA & 0 \\
\hline 20 & France, OECD MEI, Manufacturing Industrial Confidence Indicator, SA & 3 \\
\hline 21 & France, Business Surveys, INSEE, Building Industry, Global, Expected Activity & 0 \\
\hline 22 & France, Business Surveys, INSEE, Building Industry, Global, Order Books Level & 0 \\
\hline 23 & France, Business Surveys, DG ECFIN, Retail Trade Confidence Indicator, Balance, SA & 0 \\
\hline 24 & France, Business Surveys, DG ECFIN, Construction Confidence Indicator, Balance, SA & 0 \\
\hline 25 & France, Service Surveys, DG ECFIN, Services Confidence Indicator, Balance, SA & 0 \\
\hline
\end{tabular}




\section{Appendix B. One-step estimation results}

Table B.1: Frequency of 25 French economic indicators in 72 successful combinations for one-step estimation

\begin{tabular}{|c|c|c|}
\hline No & Freq. & Name of series \\
\hline 24 & 22 & France, Business Surveys, DG ECFIN, Construction Confidence Indicator, Balance, SA (Business survey) \\
\hline 1 & 21 & France, Capacity Utilization, Total Industry, SA \\
\hline 12 & 20 & France, Foreign Trade, Export, Calendar Adjusted, SA, EUR \\
\hline 8 & 19 & France, Metropolitan, Unemployment, Job Seekers, Men, Total, Categories A, B \& C, Calendar Adjusted, SA \\
\hline 23 & 19 & France, Business Surveys, DG ECFIN, Retail Trade Confidence Indicator, Balance, SA (Business survey) \\
\hline 11 & 18 & France, Foreign Trade, Trade Balance, Calendar Adjusted, SA, EUR \\
\hline 4 & 16 & France, OECD MEI, Retail Trade Orders Intentions, SA (Business survey) \\
\hline 7 & 15 & France, OECD MEI, Total Retail Trade (Volume), SA, Change $\mathrm{P} / \mathrm{P}$ \\
\hline 9 & 15 & France, OECD MEI, Manufacturing Finished Goods Stocks Level, SA \\
\hline 17 & 13 & Japan, Economic Sentiment Surveys, ZEW, Financial Market Report, Stock Market, Nikkei 225, Balance \\
\hline 18 & 12 & United States, Equity Indices, S\&P, 500, Index (Shiller), Cyclically Adjusted P/E Ratio (CAPE) \\
\hline 13 & 11 & France, Foreign Trade, Import, Calendar Adjusted, SA, EUR \\
\hline 6 & 10 & France, OECD MEI, Production Of Total Industry, SA, Index \\
\hline 14 & 10 & Taux de référence des bons de trésor à 3 mois - monthly average \\
\hline 16 & 10 & United Kingdom, Equity Indices, FTSE, All-Share, Index, Price Return, End of Period, GBP \\
\hline 22 & 10 & France, Business Surveys, INSEE, Building Industry, Global, Order Books Level \\
\hline 3 & 8 & France, Domestic Trade, Vehicle Sales \& Registrations, New, Passenger Cars, Total, Calendar Adjusted, SA \\
\hline 25 & 8 & France, Service Surveys, DG ECFIN, Services Confidence Indicator, Balance, SA \\
\hline 2 & 7 & France, Consumer Surveys, INSEE, Consumer Confidence Indicator, Synthetic Index, SA \\
\hline 15 & 7 & Taux de référence des bons de trésor à 12 mois - monthly average \\
\hline 19 & 6 & France, OECD MEI, Manufacturing Business Situation Future, SA \\
\hline 20 & 5 & France, OECD MEI, Manufacturing Industrial Confidence Indicator, SA \\
\hline 21 & 4 & France, Business Surveys, INSEE, Building Industry, Global, Expected Activity \\
\hline 5 & 2 & France, OECD MEI, CPI All Items, Change Y/Y \\
\hline 10 & 0 & France, Economic Sentiment Surveys, ZEW, Financial Market Report, Stock Market, CAC-40, Balance \\
\hline
\end{tabular}

The numbers in the last column stand for the length of lag of data updates publication, in months 
Table B.2: Crises and their most descriptive sets of economic indicators

\begin{tabular}{|c|c|c|c|c|c|c|}
\hline Crisis & \multicolumn{4}{|c|}{ Composition } & FPS & QPS \\
\hline \hline \multirow{3}{*}{ March 1992-October 1993 } & 7 & 8 & 11 & 22 & 0.0000 & 0.0142 \\
\cline { 2 - 7 } & 9 & 12 & 18 & 23 & 0.0000 & 0.0331 \\
\cline { 2 - 7 } & 9 & 14 & 17 & 23 & 0.0000 & 0.0580 \\
\hline \multirow{3}{*}{ April 1995-January 1997 } & 3 & 4 & 11 & 24 & 0.1828 & 0.1141 \\
\cline { 2 - 7 } & 6 & 8 & 12 & 25 & 0.1828 & 0.1171 \\
\cline { 2 - 7 } & 7 & 8 & 11 & 22 & 0.1828 & 0.1216 \\
\hline \multirow{3}{*}{ January 2001-June 2003 } & 3 & 9 & 12 & 25 & 0.0000 & 0.0108 \\
\cline { 2 - 7 } & 2 & 11 & 16 & 24 & 0.0000 & 0.0460 \\
\cline { 2 - 7 } & 4 & 7 & 17 & 24 & 0.0000 & 0.0477 \\
\hline \multirow{3}{*}{ January 2008-June 2009 } & 3 & 9 & 12 & 25 & 0.0000 & 0.0108 \\
\cline { 2 - 7 } & 2 & 11 & 16 & 24 & 0.0000 & 0.0460 \\
\cline { 2 - 7 } & 4 & 7 & 17 & 24 & 0.0000 & 0.0477 \\
\hline \multirow{3}{*}{ October 2011-January 2013 } & 7 & 8 & 11 & 22 & 0.0000 & 0.0205 \\
\cline { 2 - 7 } & 3 & 9 & 12 & 25 & 0.0625 & 0.0828 \\
\cline { 2 - 7 } & 7 & 8 & 11 & 23 & 0.0625 & 0.0870 \\
\hline
\end{tabular}

Note: Here the QPS and FPS are calculated for each recession period only.

Table B.3: Top 25 combinations with the lowest $Q P S, F P S$ and the highest Corr . The first 8 entries belong to the best $10 \%$ by three indicators simultaneously

\begin{tabular}{|c|c|c|c|c|c|c|c|c|c|c|c|c|}
\hline \multirow{2}{*}{$\begin{array}{c}\text { Retained combinations } \\
\text { Combination } 1 \\
\end{array}$} & \multirow{2}{*}{$\frac{\text { Rating }}{1}$} & \multicolumn{4}{|c|}{ Component series } & \multirow{2}{*}{$\frac{\text { FPS }}{35}$} & \multirow{2}{*}{$\begin{array}{c}\text { QPS } \\
0.1287\end{array}$} & \multirow{2}{*}{$\begin{array}{c}\text { Corr } \\
0.7155\end{array}$} & \multicolumn{4}{|c|}{ Factor loadings } \\
\hline & & 4 & 7 & 17 & 24 & & & & 0.3665 & 0.1006 & -0.0026 & 0.4463 \\
\hline - & 7 & 8 & 12 & 23 & 24 & 49 & 0.1493 & 0.7554 & -0.1454 & 0.0247 & 0.1301 & 0.0005 \\
\hline Combination 2 & 2 & 2 & 11 & 16 & 24 & 39 & 0.1315 & 0.6899 & 0.1775 & -0.0584 & 0.6137 & 0.3779 \\
\hline Combination 3 & 3 & 3 & 4 & 11 & 24 & 45 & 0.1254 & 0.7491 & 0.0001 & 0.1807 & -0.0461 & 0.8876 \\
\hline Combination 4 & 4 & 4 & 9 & 19 & 24 & 46 & 0.1328 & 0.7006 & 0.3058 & -0.0799 & 0.6722 & 0.3337 \\
\hline Combination 5 & 5 & 4 & 7 & 11 & 24 & 46 & 0.1412 & 0.7082 & 0.3139 & 0.0933 & -0.0768 & 0.3958 \\
\hline Combination 6 & 6 & 8 & 18 & 23 & 24 & 47 & 0.1184 & 0.6815 & 0.0738 & -0.0452 & -0.0805 & -0.3292 \\
\hline Combination 7 & 8 & 7 & 8 & 11 & 23 & 50 & 0.1492 & 0.5607 & 0.0216 & -0.1829 & -0.0371 & -0.0013 \\
\hline - & 9 & 8 & 9 & 15 & 23 & 54 & 0.1674 & 0.5506 & -0.1125 & -0.0945 & 0.0344 & 0.1510 \\
\hline- & 10 & 1 & 8 & 16 & 22 & 58 & 0.1963 & 0.5929 & 0.4595 & 0.0025 & 0.7876 & 0.0015 \\
\hline- & 11 & 1 & 9 & 13 & 18 & 58 & 0.2135 & 0.5346 & 0.0983 & -0.1404 & 0.0905 & -0.0010 \\
\hline- & 12 & 4 & 9 & 12 & 24 & 59 & 0.1656 & 0.6488 & 0.2292 & -0.0746 & 0.1633 & 0.6130 \\
\hline- & 13 & 1 & 4 & 13 & 15 & 62 & 0.2091 & 0.5255 & 0.2255 & 0.1715 & 0.2888 & -0.0014 \\
\hline- & 14 & 4 & 8 & 11 & 23 & 64 & 0.1724 & 0.5033 & 0.0880 & -0.2649 & -0.0377 & -0.0031 \\
\hline- & 15 & 4 & 8 & 19 & 24 & 64 & 0.1795 & 0.6511 & 0.3272 & -0.0022 & 0.5487 & 0.3608 \\
\hline- & 16 & 15 & 16 & 17 & 24 & 64 & 0.2092 & 0.5597 & -0.0010 & 1.0500 & -0.0027 & 0.3222 \\
\hline- & 17 & 9 & 12 & 18 & 23 & 65 & 0.1993 & 0.5321 & -0.2665 & 0.0362 & 0.0384 & 0.1614 \\
\hline- & 18 & 18 & 22 & 23 & 24 & 67 & 0.2147 & 0.4249 & 0.0219 & 0.0130 & 0.0738 & 0.0002 \\
\hline- & 19 & 7 & 14 & 24 & 25 & 68 & 0.2233 & 0.4967 & 0.0016 & -0.0004 & 0.5101 & 0.0428 \\
\hline- & 20 & 7 & 8 & 11 & 24 & 69 & 0.1702 & 0.6538 & -0.1141 & -0.0003 & -0.0066 & -0.8400 \\
\hline- & 21 & 14 & 15 & 18 & 24 & 70 & 0.1799 & 0.5312 & 0.0636 & 0.0063 & 0.0082 & 0.7306 \\
\hline- & 22 & 11 & 16 & 21 & 22 & 71 & 0.1862 & 0.5639 & -0.0006 & 0.9812 & 0.0170 & -0.0007 \\
\hline- & 23 & 1 & 12 & 13 & 17 & 71 & 0.1863 & 0.5439 & 0.8973 & 0.2825 & 0.3013 & 0.0495 \\
\hline- & 24 & 6 & 8 & 18 & $\begin{array}{lll}22 & 39\end{array}$ & 71 & 0.2058 & 0.4326 & 0.0262 & -0.2072 & 0.0283 & 0.0328 \\
\hline & 25 & 12 & 14 & 20 & 23 & 72 & 0.1912 & 0.5221 & 0.1444 & 0.0687 & 0.6750 & 0.1026 \\
\hline
\end{tabular}

Note: The series with the highest loadings are in bold. Retained combinations are the combinations retained for the

one-step analysis. The second-ranked combination in not included as it produces extra signals 
Figure B.1. Results of one-step estimation: filtered probability to be in recession in a current period (blue line) vs OECD recession dating (shaded area, 1 corresponds to recession, 0 to expansion).

\section{One-step combination 1}

4 - France, OECD MEI, Retail Trade Orders Intentions, SA

7 - France, OECD MEI, Total Retail Trade (Volume), SA, Change P/P

17 - Japan, Economic Sentiment Surveys, ZEW, Financial Market Report, Stock Market, Nikkei 225, Balance 24 - France, Business Surveys, DG ECFIN, Construction Confidence Indicator, Balance, SA

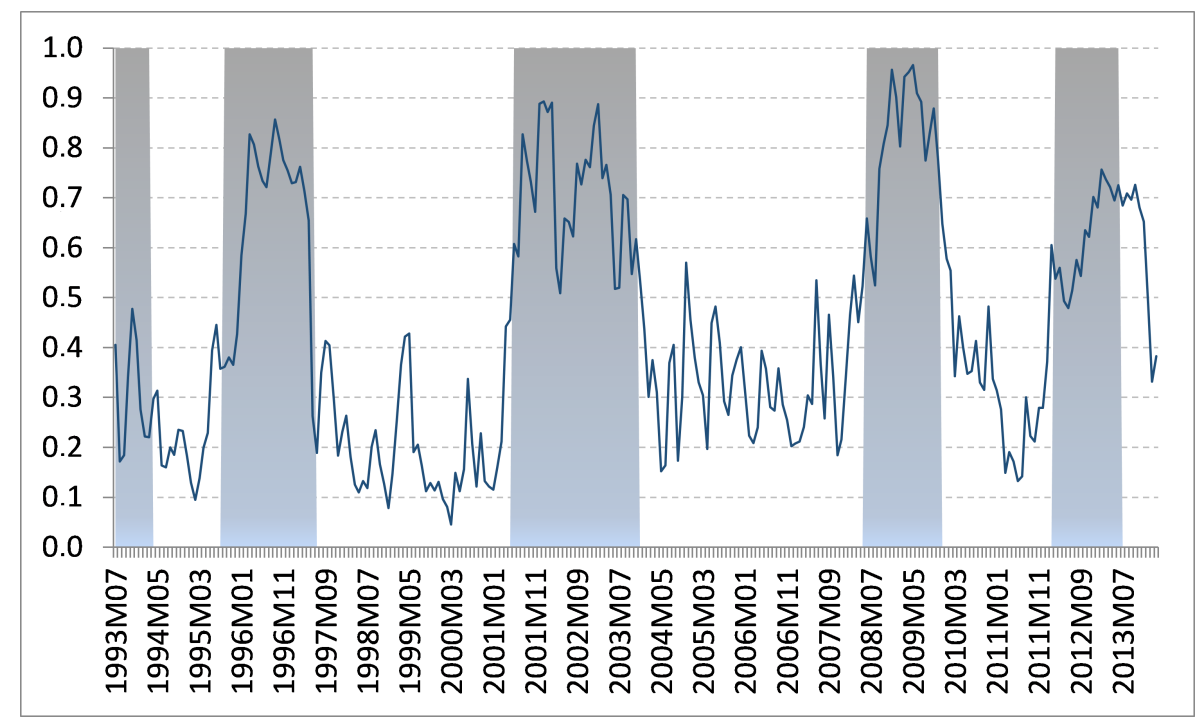




\section{One-step combination 2}

3 - France, Domestic Trade, Vehicle Sales \& Registrations, New, Passenger Cars, Total, Calendar Adjusted, SA 4 - France, OECD MEI, Retail Trade Orders Intentions, SA

11 - France, Foreign Trade, Trade Balance, Calendar Adjusted, SA, EUR

24 - France, Business Surveys, DG ECFIN, Construction Confidence Indicator, Balance, SA

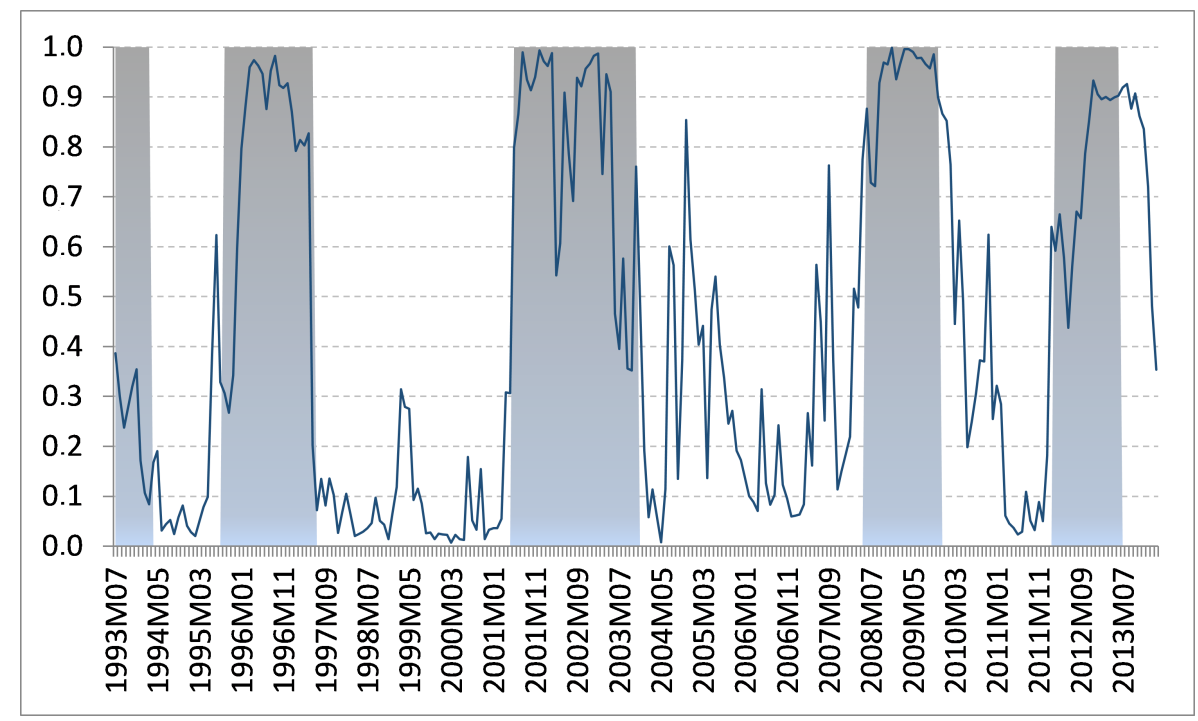

\section{One-step combination 3}

4 - France, OECD MEI, Retail Trade Orders Intentions, SA

9 - France, OECD MEI, Manufacturing Finished Goods Stocks Level, SA

19 - France, OECD MEI, Manufacturing Business Situation Future, SA

24 - France, Business Surveys, DG ECFIN, Construction Confidence Indicator, Balance, SA

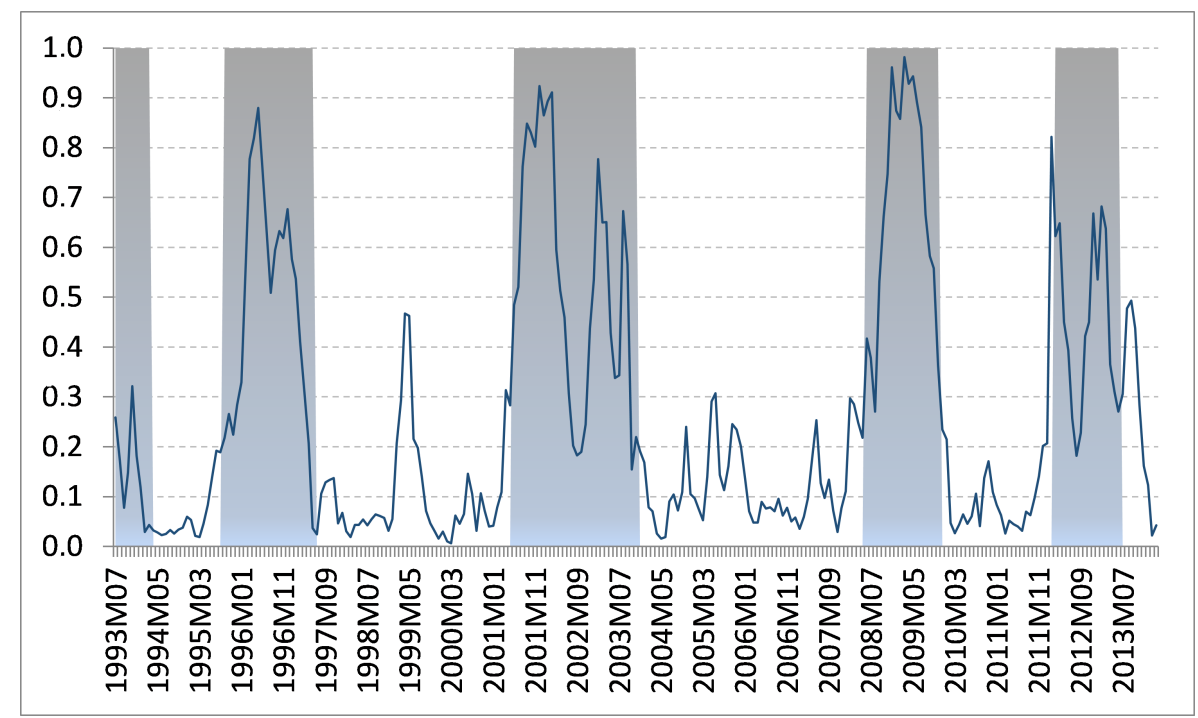




\section{One-step combination 4}

4 - France, OECD MEI, Retail Trade Orders Intentions, SA

7 - France, OECD MEI, Total Retail Trade (Volume), SA, Change P/P

11 - France, Foreign Trade, Trade Balance, Calendar Adjusted, SA, EUR

24 - France, Business Surveys, DG ECFIN, Construction Confidence Indicator, Balance, SA

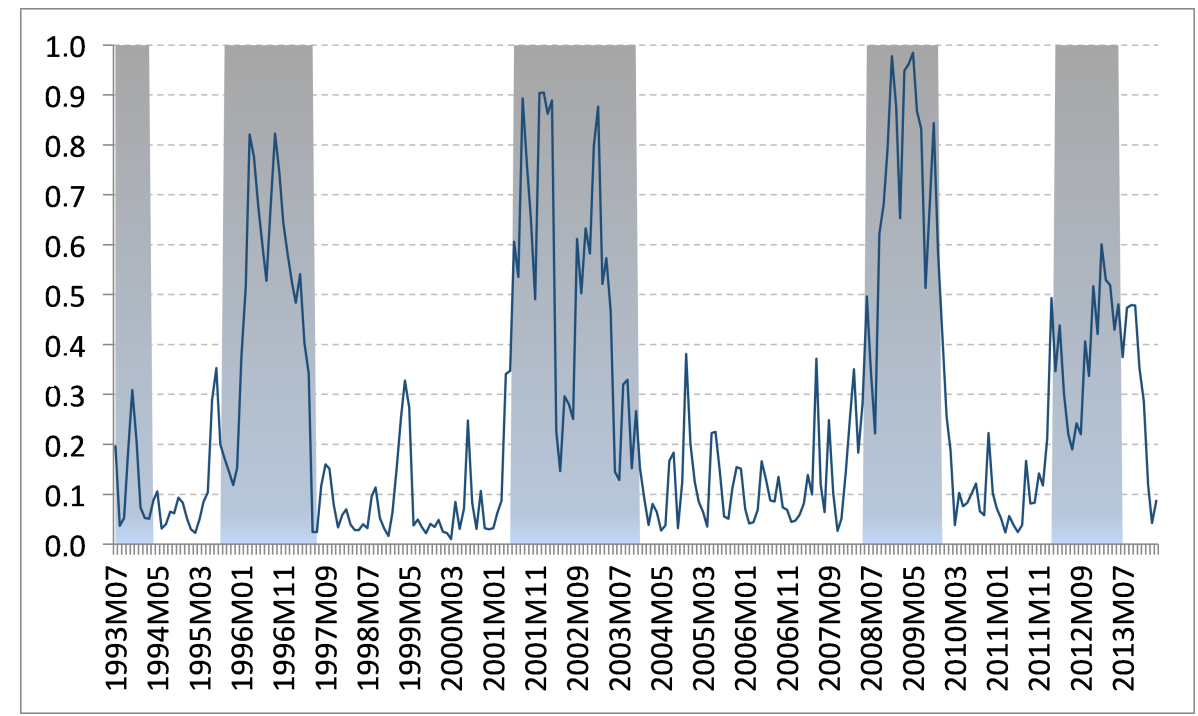

\section{One-step combination 5}

8 - Unemployed, total

18 - United States, Equity Indices, S\&P, 500, Index (Shiller), Cyclically Adjusted P/E Ratio (CAPE)

23 - France, Business Surveys, DG ECFIN, Retail Trade Confidence Indicator, Balance, SA

24 - France, Business Surveys, DG ECFIN, Construction Confidence Indicator, Balance, SA

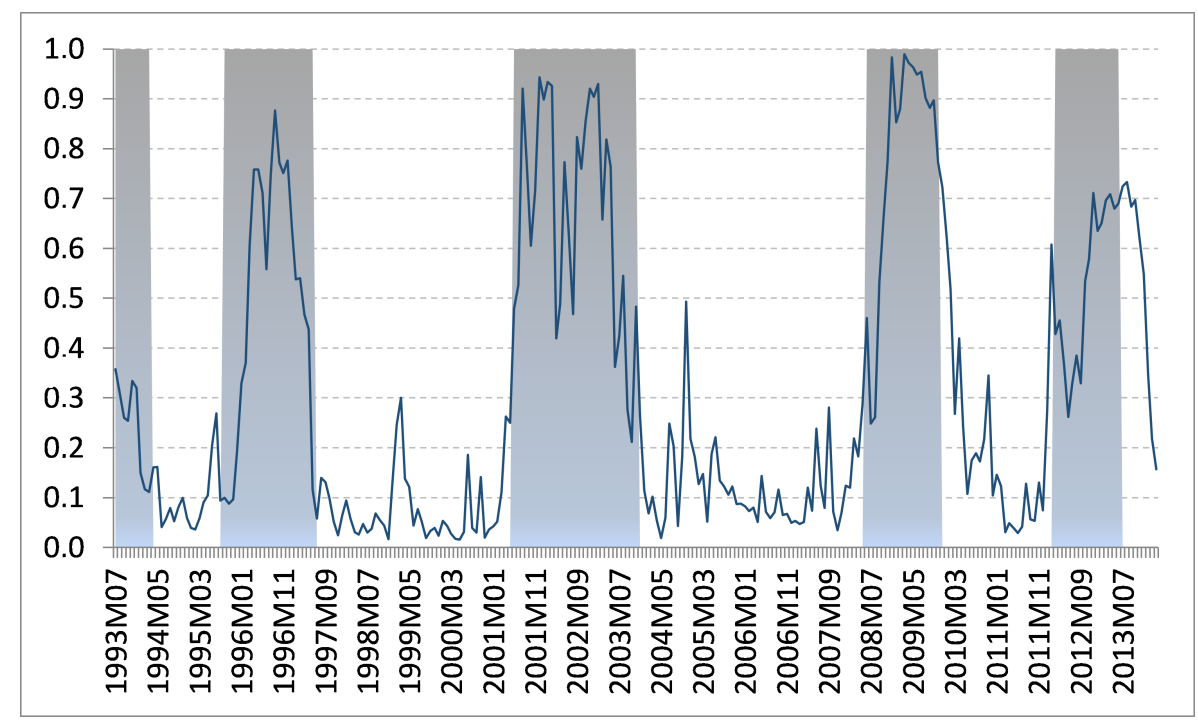




\section{One-step combination 6}

8 - Unemployed, total

12 - France, Foreign Trade, Export, Calendar Adjusted, SA, EUR

23 - France, Business Surveys, DG ECFIN, Retail Trade Confidence Indicator, Balance, SA

24 - France, Business Surveys, DG ECFIN, Construction Confidence Indicator, Balance, SA

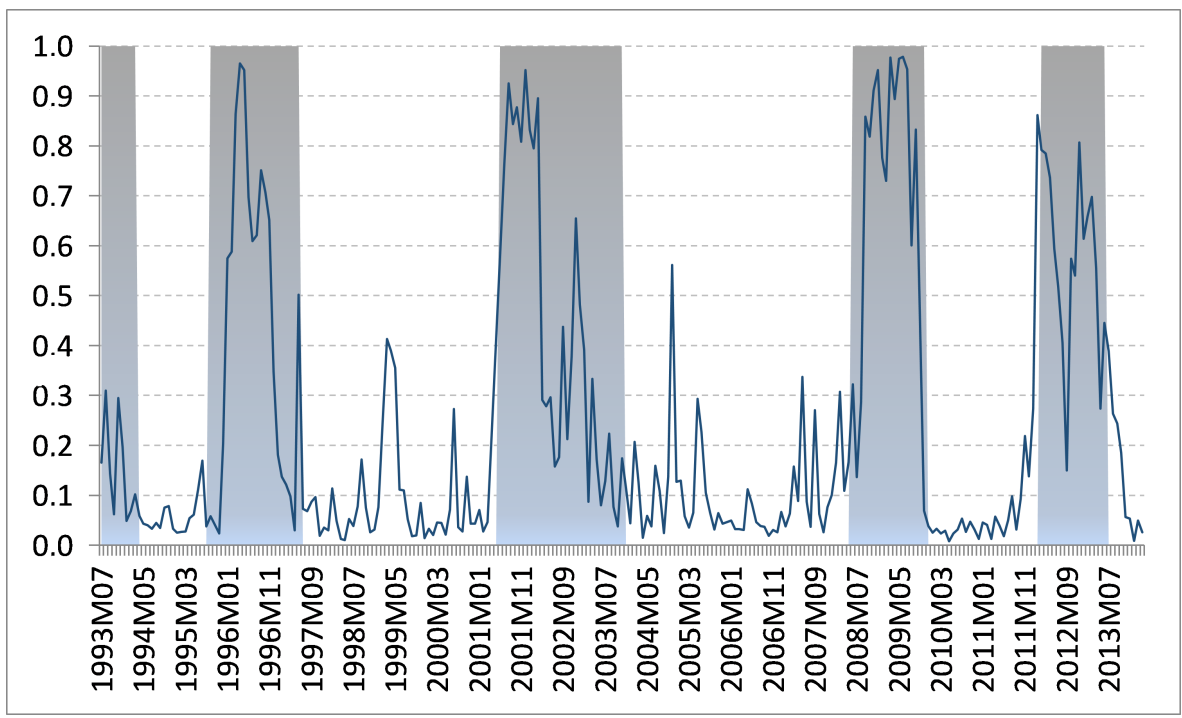

\section{One-step combination 7}

7 - France, OECD MEI, Total Retail Trade (Volume), SA, Change P/P

8 - Unemployed, total

11 - France, Foreign Trade, Trade Balance, Calendar Adjusted, SA, EUR

23 - France, Business Surveys, DG ECFIN, Retail Trade Confidence Indicator, Balance, SA

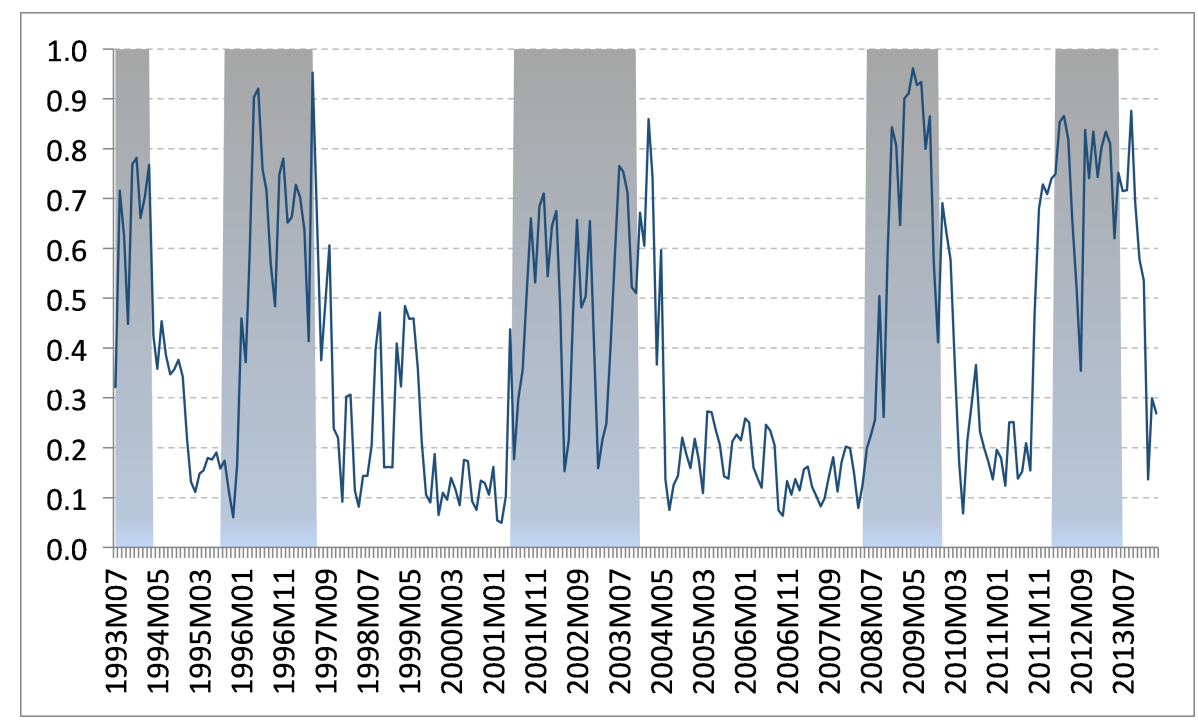




\section{Finally selected information set}

Figure B.2. The filtered probability of recession, estimated with one-step method on 13 series of the finally selected information set (blue line) vs OECD recession dating (shaded area, 1 corresponds to recession)

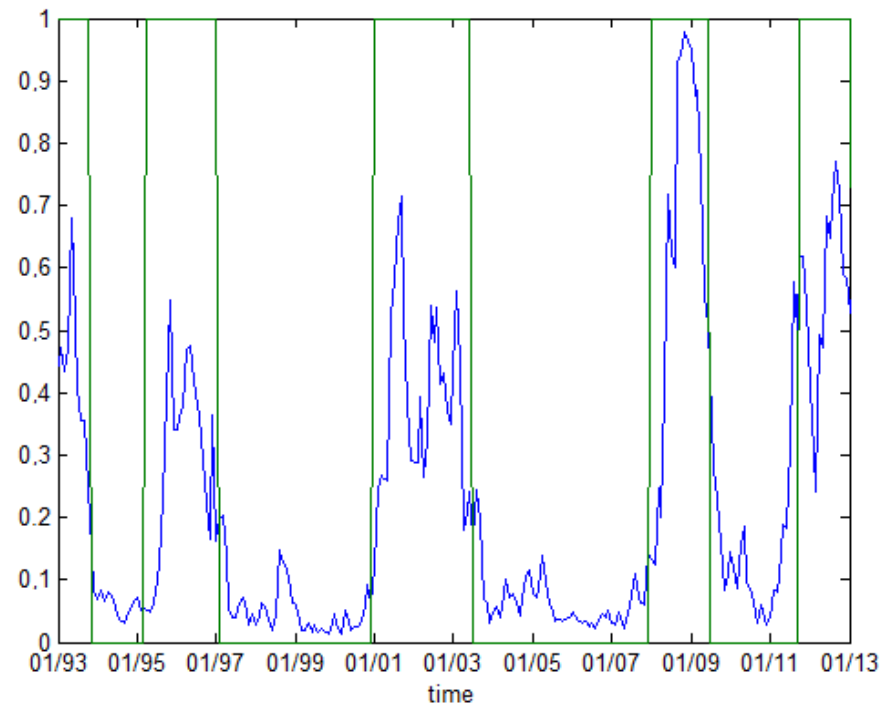

The blue line corresponds to the filtered probability of recession, the green line corresponds to the OECD turning points

Series:

4 - France, OECD MEI (Enquete de Conjoncture INSEE), Retail Trade Orders Intentions, SA;

8 - Unemployed, total

19 - France, OECD MEI (Enquete de Conjoncture INSEE), Manufacturing Business Situation Future, SA

24 - France, Business Surveys, DG ECFIN, Construction Confidence Indicator, Balance, SA

2 - France, Consumer Surveys, INSEE, Consumer Confidence Indicator, Synthetic Index, SA

3 - France, Domestic Trade, Vehicle Sales \& Registrations, New, Passenger Cars, Total, Calendar Adjusted, SA

7 - France, OECD MEI, Total Retail Trade (Volume), SA, Change P/P

9 - France, OECD MEI, Manufacturing Finished Goods Stocks Level, SA

11 - France, Foreign Trade, Trade Balance, Calendar Adjusted, SA, EUR

12 - France, Foreign Trade, Export, Calendar Adjusted, SA, EUR

17 - Japan, Economic Sentiment Surveys, ZEW, Financial Market Report, Stock Market, Nikkei 225, Balance

18 - United States, Equity Indices, S\&P, 500, Index (Shiller), Cyclically Adjusted P/E Ratio (CAPE)

23 - France, Business Surveys, DG ECFIN, Retail Trade Confidence Indicator, Balance, SA 


\section{Appendix C. Estimation results for one-step and two-step methods}

Table C.1: Estimated parameters, one-step and two-step methods

\begin{tabular}{|c|c|c|c|c|c|c|c|c|c|}
\hline \multirow[b]{2}{*}{ Parameters } & \multicolumn{2}{|c|}{ Two-step } & \multicolumn{7}{|c|}{ One-step } \\
\hline & $\begin{array}{c}\text { (switch in } \\
\mu)\end{array}$ & $\begin{array}{l}\text { (switch in } \\
\mu \text { and } \sigma^{2} \text { ) }\end{array}$ & $\begin{array}{c}\text { Comb } \\
1\end{array}$ & $\begin{array}{c}\text { Comb } \\
2\end{array}$ & $\begin{array}{c}\text { Comb } \\
3\end{array}$ & $\begin{array}{c}\text { Comb } \\
4\end{array}$ & $\begin{array}{c}\text { Comb } \\
5\end{array}$ & $\begin{array}{c}\text { Comb } \\
6\end{array}$ & $\begin{array}{c}\text { Comb } \\
7\end{array}$ \\
\hline$\phi_{1}$ & 0.0010 & 0.0012 & $0.0018^{*}$ & $-0.0142^{*}$ & $-0.0031^{*}$ & $-0.0033^{*}$ & $0.8348^{*}$ & $0.1864^{*}$ & $0.0753^{*}$ \\
\hline$\phi_{2}$ & $0.8926^{*}$ & $0.8685^{*}$ & 0.0016 & -0.0070 & $0.0021^{*}$ & 0.0049 & $-0.2047^{*}$ & $0.7788^{*}$ & $0.6955^{*}$ \\
\hline$\psi_{11}$ & & - & $-0.4524^{*}$ & $-0.4922^{*}$ & $-0.3708^{*}$ & $-0.3659 *$ & 0.0027 & $0.0626^{*}$ & $-0.7269 *$ \\
\hline$\psi_{12}$ & & - & $0.0046^{*}$ & $-0.2011^{*}$ & $-0.0063^{*}$ & -0.0012 & $-0.0027^{*}$ & $0.1096^{*}$ & $-0.4214^{*}$ \\
\hline$\psi_{21}$ & & - & $-0.7354^{*}$ & $-0.3727^{*}$ & $0.9060^{*}$ & $-0.7475^{*}$ & $0.9889^{*}$ & $-0.5624^{*}$ & $0.2608^{*}$ \\
\hline$\psi_{22}$ & & - & $-0.4208^{*}$ & 0.0016 & 0.0119 & $-0.4271^{*}$ & $-0.0003^{*}$ & $-0.2637^{*}$ & $0.3266^{*}$ \\
\hline$\psi_{31}$ & & - & $0.8955^{*}$ & $-0.6637^{*}$ & $0.1708^{*}$ & $-0.6240^{*}$ & $0.5139^{*}$ & $0.4689^{*}$ & $-0.6276^{*}$ \\
\hline$\psi_{32}$ & & - & -0.0046 & $-0.2873^{*}$ & $0.1148^{*}$ & $-0.2025^{*}$ & $0.3528^{*}$ & $0.2521^{*}$ & $-0.2046^{*}$ \\
\hline$\psi_{41}$ & & - & -0.0023 & $-0.0043^{*}$ & $-0.0014^{*}$ & -0.0056 & $0.0007^{*}$ & $0.0040^{*}$ & $0.0007^{*}$ \\
\hline$\psi_{42}$ & & - & $-0.0025^{*}$ & $-0.0075^{*}$ & $-0.0022^{*}$ & $-0.1115^{*}$ & -0.0003 & $-0.0043^{*}$ & $-0.0031^{*}$ \\
\hline$\sigma_{1}$ & & - & 0.6622 & 0.6343 & 0.6470 & 0.6589 & 0.6228 & 0.7256 & 0.6714 \\
\hline$\sigma_{2}$ & & - & 0.6736 & 0.6331 & 0.8150 & 0.6823 & 0.9353 & 0.6539 & 0.7130 \\
\hline$\sigma_{3}$ & & - & 0.7925 & 0.6590 & 0.7136 & 0.6589 & 0.7410 & 0.7500 & 0.6609 \\
\hline$\sigma_{4}$ & & - & 0.7244 & 1.0006 & 0.6676 & 0.7260 & 0.6853 & 0.6905 & 0.7864 \\
\hline$\gamma_{1}$ & & - & $0.3665^{*}$ & $0.0001^{*}$ & $0.3058^{*}$ & $0.3139^{*}$ & $0.0738^{*}$ & $-0.1454^{*}$ & $0.0216^{*}$ \\
\hline$\gamma_{2}$ & & - & $0.1006^{*}$ & $0.1807^{*}$ & $-0.0799^{*}$ & $0.0933^{*}$ & $-0.0452^{*}$ & $0.0247^{*}$ & $-0.1829^{*}$ \\
\hline$\gamma_{3}$ & & - & $-0.0026^{*}$ & $-0.0461^{*}$ & $0.6722^{*}$ & $-0.0768^{*}$ & $-0.0805^{*}$ & $0.1301^{*}$ & $-0.0371^{*}$ \\
\hline$\gamma_{4}$ & & - & $0.4463^{*}$ & $0.8876^{*}$ & $0.3337^{*}$ & $0.3958^{*}$ & $-0.3292^{*}$ & $0.0005^{*}$ & $-0.0013^{*}$ \\
\hline$\mu_{0}$ & $1.0452^{*}$ & $1.2251^{*}$ & $0.3089^{*}$ & $0.4710^{*}$ & $0.2107^{*}$ & $0.3075^{*}$ & $0.8431^{*}$ & $0.6056^{*}$ & $0.7906^{*}$ \\
\hline$\mu_{1}$ & $-1.7789^{*}$ & $-1.5245^{*}$ & $-0.3162^{*}$ & $-0.5072^{*}$ & $-0.7062^{*}$ & $-0.8129^{*}$ & $-0.2725^{*}$ & $-1.6863^{*}$ & $-1.1919^{*}$ \\
\hline$\sigma_{\eta 0}$ & $0.5770^{*}$ & $0.4028^{*}$ & - & - & - & - & - & - & - \\
\hline$\sigma_{\eta 1}$ & $0.5770^{*}$ & $0.7524^{*}$ & - & - & - & - & - & - & - \\
\hline$p_{0}$ & $0.9532^{*}$ & $0.9432^{*}$ & 0.9549 & 0.9585 & 0.9728 & 0.9673 & 0.9636 & 0.9650 & 0.9352 \\
\hline$p_{1}$ & $0.9029^{*}$ & $0.9149^{*}$ & 0.9442 & 0.9525 & 0.9284 & 0.9120 & 0.9385 & 0.8949 & 0.9011 \\
\hline
\end{tabular}

For the composition of Combination i see Table B.3 and Table A.2. Estimates marked with * are significant on $5 \%$ level of confidence probability. $\sigma_{\eta 0}$ and $\sigma_{\eta 1}$ stand for the standard error of $\eta_{t}$ (the stochastic term in factor dynamics) in expansion and recession states, respectively. 